University of Nebraska - Lincoln

DigitalCommons@University of Nebraska - Lincoln

\title{
The Aerosphere as a Network Connector of Organisms and Their Diseases
}

Jeremy D. Ross

Eli S. Bridge

Diann J. Prosser

John Y. Takekawa

Follow this and additional works at: https://digitalcommons.unl.edu/usgsstaffpub

Part of the Geology Commons, Oceanography and Atmospheric Sciences and Meteorology Commons, Other Earth Sciences Commons, and the Other Environmental Sciences Commons

This Article is brought to you for free and open access by the US Geological Survey at DigitalCommons@University of Nebraska - Lincoln. It has been accepted for inclusion in USGS Staff -- Published Research by an authorized administrator of DigitalCommons@University of Nebraska - Lincoln. 


\title{
The Aerosphere as a Network Connector of Organisms and Their Diseases
}

\author{
Jeremy D. Ross, Eli S. Bridge, Diann J. Prosser, and John Y. Takekawa
}

\begin{abstract}
Aeroecological processes, especially powered flight of animals, can rapidly connect biological communities across the globe. This can have profound consequences for evolutionary diversification, energy and nutrient transfers, and the spread of infectious diseases. The latter is of particular consequence for human populations, since migratory birds are known to host diseases which have a history of transmission into domestic poultry or even jumping to human hosts. In this chapter, we present a scenario under which a highly pathogenic avian influenza (HPAI) strain enters North America from East Asia via postmolting waterfowl migration. We use an agent-based model (ABM) to simulate the movement and disease transmission among $10^{6}$ generalized waterfowl agents originating from ten molting locations in eastern Siberia, with the HPAI seeded in only $\sim 10^{2}$ agents at one of these locations. Our ABM tracked the disease dynamics across a very large grid of sites as well as individual agents, allowing us to examine the spatiotemporal patterns of change in virulence of the HPAI infection as well as waterfowl host susceptibility to the disease. We concurrently simulated a 12-station disease monitoring network in the northwest USA and Canada in order to assess the potential efficacy of these sites to detect and confirm the arrival of HPAI. Our findings indicated that HPAI spread was initially facilitated but eventually subdued by the migration of host agents. Yet,
\end{abstract}

J.D. Ross $(\square) \cdot$ E.S. Bridge

Oklahoma Biological Survey, University of Oklahoma, Norman, OK, USA

e-mail: rossjd@ou.edu; ebridge@ou.edu

D.J. Prosser

USGS Patuxent Wildlife Research Center, Beltsville, MD, USA

e-mail: dprosser@usgs.gov

J.Y. Takekawa

Audubon California, Richardson Bay Audubon Center and Sanctuary, Tiburon, CA, USA

e-mail: jtakekawa@audubon.org 
during the 90-day simulation, selective pressures appeared to have distilled the HPAI strain to its most virulent form (i.e., through natural selection), which was counterbalanced by the host susceptibility being conversely reduced (i.e., through genetic predisposition and acquired immunity). The monitoring network demonstrated wide variation in the utility of sites; some were clearly better at providing early warnings of HPAI arrival, while sites further from the disease origin exposed the selective dynamics which slowed the spread of the disease albeit with the result of passing highly virulent strains into southern wintering locales (where human impacts are more likely). Though the ABM presented had generalized waterfowl migration and HPAI disease dynamics, this exercise demonstrates the power of such simulations to examine the extremely large and complex processes which comprise aeroecology. We offer insights into how such models could be further parameterized to represent HPAI transmission risks as well as how ABMs could be applied to other aeroecological questions pertaining to individual-based connectivity.

Movement through the air, once achieved, could be perceived as an entry to all areas of the world touched by the wind. The barriers that affect biological connectivity in terrestrial or aquatic ecosystems are much less pronounced in wide-open skies. Yet, the air column and dynamic processes therein which comprise the "aerosphere" present their own ecological pressures, which can dictate the flow of volant organisms relative to the underlying landscape, other airborne species and materials, and the airmass itself. In the case of vertebrates, sustained movements through the aerosphere are the result of powered flights where the direction, duration, and daily distance traveled are both intrinsically and extrinsically controlled. The balance between a genetically mediated migratory program and phenotypic flexibility produces complex interactions that further mediate the flight behaviors of vertebrates. The ease with which a species can transverse a landscape springs from the sum effect of piecemeal decisions (Taylor et al. 1993). Because of this, characterizing the movements of a species or population likely requires that we examine flight through the aerosphere at the lowest denominator: the individual (Morales et al. 2010).

Advances in tracking individuals using technology such as light-level archival geolocators, satellite transmitters, GPS tags, and tissue stable isotope analyses have begun to reveal much about individual variation and population patterns in vertebrate flight behavior (Cooke et al. 2004; Hobson and Norris 2008; Robinson et al. 2010; Bridge et al. 2011; McKinnon et al. 2013; Kays et al. 2015) or, possibly, in-flight physiology (Gumus et al. 2015). However, scaling such efforts to more widely encompassing levels remains logistically challenging if not prohibitively expensive (Cagnacci et al. 2010; Hebblewhite and Haydon 2010). Because of this, current endeavors to track individual movements may be restricted in their ability to 
broadly represent movement behavior variation throughout species' regional or range-wide populations. Data-informed models of individual movements within a simulation framework show promise in filling otherwise-unreachable knowledge gaps regarding biological phenomena (DeAngelis and Mooij 2005; Tang and Bennett 2010). Relevant to this volume is how vertebrates move through the aerosphere and, by extension, the ease with which optimized flight strategies can connect populations and biological communities across broad spatial scales (Alerstam 2011).

The implications of better resolving individual movements through the aerosphere as a component of geographic connectivity are likely to enhance various biological disciplines: from evolution, landscape ecology, conservation biology, resource management, and behavior to broadly integrative macrosystem studies. For instance, it is generally thought that capacity for long-distance flight often reduces the impermeability of landscape features that would otherwise be barriers to species with greater movement restrictions (Wiens 1976; Taylor et al. 1993), including non-migratory birds (Harris and Reed 2002). Because of this, flying animals with expansive ranges such as migratory birds are often found to show only modest, if any, phylogeographic variation (Zink 1996; Sutherland et al. 2000; von Rönn et al. 2016). Yet, in many cases migratory constraints within a species appear to have contributed to some degree of geographic diversification (see Chap. 11; Irwin 2002; Pérez-Tris et al. 2004; Delmore and Irwin 2014). By simulating potentially subtle barriers to migratory and breeding dispersal using agent-based models (ABMs; alternatively, "individual-based models"), we may have the opportunity to uncover evolutionarily significant patterns within highly vagile species. This includes integrating the available information about the species' migratory biology and simulating probable real-world scenarios (Bowlin et al. 2010; MacPherson and Gras 2016).

ABM simulations extend our ability to model natural phenomena to include complex interactions among multiple different types of agents. These may include vector agents that are capable of traversing the simulation arena or static agents that occupy the same spatial arena but may dynamically change during the simulation (e.g., a vegetated area which sprouts, blooms, seeds, and senesces over time). Since ABMs can be tailored to any geographic or temporal scale, even slow-developing or locally subtle patterns among agent interactions can be examined, despite the complexity of ecological or evolutionary processes. For example, the seasonal flow of energy and nutrients as a result of animal migration may be difficult to quantify using standard field techniques, since the deposition of waste or carcasses are relatively rarely detected events (outside of huge aggregation sites). Yet, we understand that migratory birds regularly move through the aerosphere to exploit seasonal pulses of resources (Alerstam et al. 2003; Bowlin et al. 2010; Shariatinajafabadi et al. 2014; Si et al. 2015), and so the influx and exodus of billions of individuals, with associated depredations and depositions along the way, certainly must collectively have a nontrivial impact in terms of the redistribution of energy and nutrients (Bauer and Hoye 2014). A properly parameterized ABM could not only outline what this redistribution might entail at stopover sites, it may also 
predict what transitory impacts this may have where migratory flight paths aggregate over otherwise unsuitable stopover habitat (e.g., over open water of the Great Lakes region of North America).

Perhaps the most pressing cause for studying connectivity among species and the landscape is the potential threat posed by continental-scale transmission of highly pathogenic avian influenza (HPAI) via migratory birds. These long-distance migrants may be the primary conduit by which certain diseases could traverse continents and jump dispersal barriers, such as mountain ranges or oceans. HPAI is of particular concern because recent outbreaks among domestic fowl in East Asia, Europe, and North America were thought to be mediated by wild birds (Okazaki et al. 2000; Hulse-Post et al. 2005; Gilbert et al. 2006; Kilpatrick et al. 2006; Alexander and Brown 2009; Feare 2010). This disease is also naturally prevalent in the environment (Winker and Gibson 2010), and it shows high transmissibility, morbidity, mutability, and potential for jumping to mammalian hosts (Kapan et al. 2006; Olsen et al. 2006; Taubenberger and Kash 2016). A worst-case scenario is that a virulent HPAI strain capable of switching hosts to infect human populations becomes spread across a wide landscape through the flights of wild birds (Tan et al. 2015). Countering disease transmission and host switching is best accomplished through a coordinated detection-and-response network (Wagner et al. 2001; Jebara 2004; Choffnes et al. 2007; Silkavute et al. 2013; Xu et al. 2013). As with any threat to human life, early and accurate detection of a disease is critical if mitigation is to be effective. These actions may include quarantines or inoculations of potentially exposed humans or similar measures among possible animal vectors, with the additional option of population culls of domestic fowl or hazing wild host populations (DeLiberto et al. 2011; Wobeser 2013).

Best management practices dictate that limited pools of funding should be directed to maximize the intended outcome. In the case of HPAI monitoring, this hinges upon one critical need: to detect the disease while there remains an opportunity to halt an outbreak. This "make-or-break" scenario puts tremendous pressure on monitoring agencies to have an expansive focus and to swiftly and accurately diagnose HPAI in the field. Accomplishing this task naively would necessitate a costly outpouring of resources just to capture the earliest signs of disease infiltration or host shifting. Coordinated monitoring networks, such as the United States Geological Service's Wildlife Health Information Sharing Partnership event reporting system (WHISPers; https://www.nwhc.usgs.gov/whispers/), show great promise at early detection of HPAI, although the efficacy of these endeavors is still reliant upon sufficient sampling, accuracy, and timely reporting by field observers.

Fail-safe disease monitoring regimes can not only be expensive and challenging to coordinate, but may be also difficult to grade for accuracy and efficacy. The static models and formulas currently used to determine sampling needs for detecting a disease hinge upon uncertainty parameters which can be broad (e.g., severity of exposure events, distribution and virulence of zoonotic infective source; Yang et al. 2007). In many cases, the assessments of how well monitoring regimes are actually functioning have mostly been limited to preparedness indicator surveys (ECDC 2007; Azziz-Baumgartner et al. 2009) or, when the system fails, a retroactive 
assessment of shortcomings (Balicer et al. 2007; Scallan 2007). As a low-cost and promising alternative, $\mathrm{ABM}$ simulations may be a useful tool for making proactive assessments of HPAI monitoring networks and possibly optimizing their effectiveness relative to cost. With this in mind, we have constructed a realistic $\mathrm{ABM}$ which simulates a hypothetical HPAI transmission into North America from Asia and concordantly tests the efficacy of a theoretical monitoring network to detect the disease before it has progressed to an outbreak stage.

The ABM presented in this chapter incorporates underlying biological principles related to both large-scale bird migration and the Susceptible-Exposed-InfectedRecovered (SEIR) model of disease dynamics (Keeling and Rohani 2008). However, instead of using static population-level metrics within the SEIR model, we have leveraged the power of the ABM simulation framework to allow the SEIR factors to dynamically evolve during the course of the simulation. This is likely to more accurately reflect the reality in nature, since viruses such as avian influenza have the capacity to rapidly mutate into more virulent strains just as their hosts have the capacity to alter their individual susceptibility and/or probability of recovery through acquired immunity (Bourouiba et al. 2011; Pybus et al. 2013). In effect, our $\mathrm{ABM}$ is designed to parameterize the probability of low-incidence, high-risk disease transmission that would otherwise be difficult to trace, even from extensive sampling regimes. Such a model is not only informed by existing knowledge but can, in turn, guide future empirical studies by exposing knowledge gaps (Harris et al. 2015), aeroecological limiting factors (Lam et al. 2012), or critical nodes within disease monitoring networks (Ferguson et al. 2006; Boyce et al. 2009).

Our entire case-study simulation is couched under the topic of this chapter-the aerosphere as a connector - to illustrate how animal movement through the air may (or may not) facilitate rapid translocations and can effectively reduce the ecological divisiveness of what would otherwise be impenetrable geographic boundaries, resulting in the mixing of biological agents over large geographic extents. Building upon the paradigm of ABM operation described in Chap. 11, we now demonstrate how movement through the aerosphere can drive interspecific dynamics in the form of intercontinental spread of disease.

\section{Constructing the Agent-Based Model}

The applicability of models of increasing complexity depends upon how well their core components are built to emulate the processes of study. Building an ABMespecially of something as complex as disease transmission, evolution, and monitoring during the intercontinental migration of a very large population of a generalized waterfowl species-required that we first start with basic models of agent movement and then added levels of increasing complexity in stages. In our case, we built the ABM in the following five major stages:

1. Parameterize the autumn migration of a generalized "waterfowl" species according to simple movement and stopover rules 
2. Include more complex rules for individual waterfowl stopover and aggregation decisions

3. Add a transmissible waterfowl-borne viral disease (i.e., HPAI) as well as individual variation in disease susceptibility among waterfowl agents

4. Incorporate mutability in HPAI virulence as well as waterfowl susceptibility as a factor of exposure

5. Simulate hypothetical monitoring stations at predetermined locations (i.e., places likely to attract stopover that were relatively close to human settlements) as the means to gauge the efficacy of single versus networked stations to detect and confirm the HPAI outbreak

In the first stage of ABM development, we consulted basic knowledge about general waterfowl migratory biology. We sourced this information from traditional monitoring efforts, such as local field surveys, standardized mark-release-recapture programs, and station-network monitoring (Bellrose and Crompton 1970; Flock 1972; Dau 1992; Moermond and Spindler 1997; Winker and Gibson 2010), as well as individual tracking data gathered using modern technology (Ely et al. 1997; Green et al. 2002; Mosbech et al. 2006; Alerstam et al. 2007; Gaidet et al. 2010; Prosser et al. 2009, 2011; Krementz et al. 2012; Takekawa et al. 2010, 2013; Ely and Franson 2014). From these collective data, we were able to broadly parameterize the timing of population movements, distributions of distances moved, and stopover duration for the generalized waterfowl species being modeled. Since we were not attempting to precisely model one species or replicate an exact situation, our ABM was simply intended to be a starting point from which it can be tailored to specific systems or questions in the future.

The ABM that we constructed was designed from the second stage onward to include more complex daily movement and stopover rules, to introduce individual variation, to model contagious disease dynamics (Brown et al. 2008; Gaidet et al. 2010), and to emulate what was the ultimate focus-evaluating the efficacy of a network of monitoring stations to detect and confirm HPAI arrival by way of aeroecological connections. Because species often have different mechanisms driving large- (i.e., continental) versus small-scale (i.e., local) navigation (see Chap. 6), we allowed for modest spatiotemporal shifts in migratory flight behavior of the generalized waterfowl species throughout the migratory period. We also incorporated simple rules to allow symptomatic birds to be more readily detected at monitoring stations (Brown and Stallknecht 2008) and for both virus and host agents to evolve as the simulation progressed and passed through the stages of the SEIR model. Below we outline the final composition of our ABM which incorporates additions from all five stages of model development.

\subsection{Populating the Arena, Agents, and Disease}

Our ABM focused on the individual movements of a generalized waterfowl species during a hypothetical 90-day autumn migration period that connected birds between 
their molting locations in eastern Siberia to wintering grounds in the southern USA or northern Mexico. This reflects a hypothetical situation where HPAI enters the Americas via southward migration of arctic-breeding birds. The arena of possible bird locations included an area extending from eastern Siberia to Iceland, Central America, and Venezuela (Fig. 17.1). This area was projected to a Lambert Azimuthal Equal Area sphere centered on $100^{\circ} \mathrm{W}$ with latitude of origin at $45^{\circ} \mathrm{N}$, which provided a meter-based overlay of the area of interest. At $10 \mathrm{~km}$ intervals along both the $x$ - and $y$-axes, we plotted a grid of possible stopover locations for agents during their migration. We excluded as possible stopover sites those grid points positioned greater than $200 \mathrm{~km}$ from land, since the waterfowl agent simulated was intended to prefer land and realistic disease monitoring capacity would be restricted to the near-coast region.

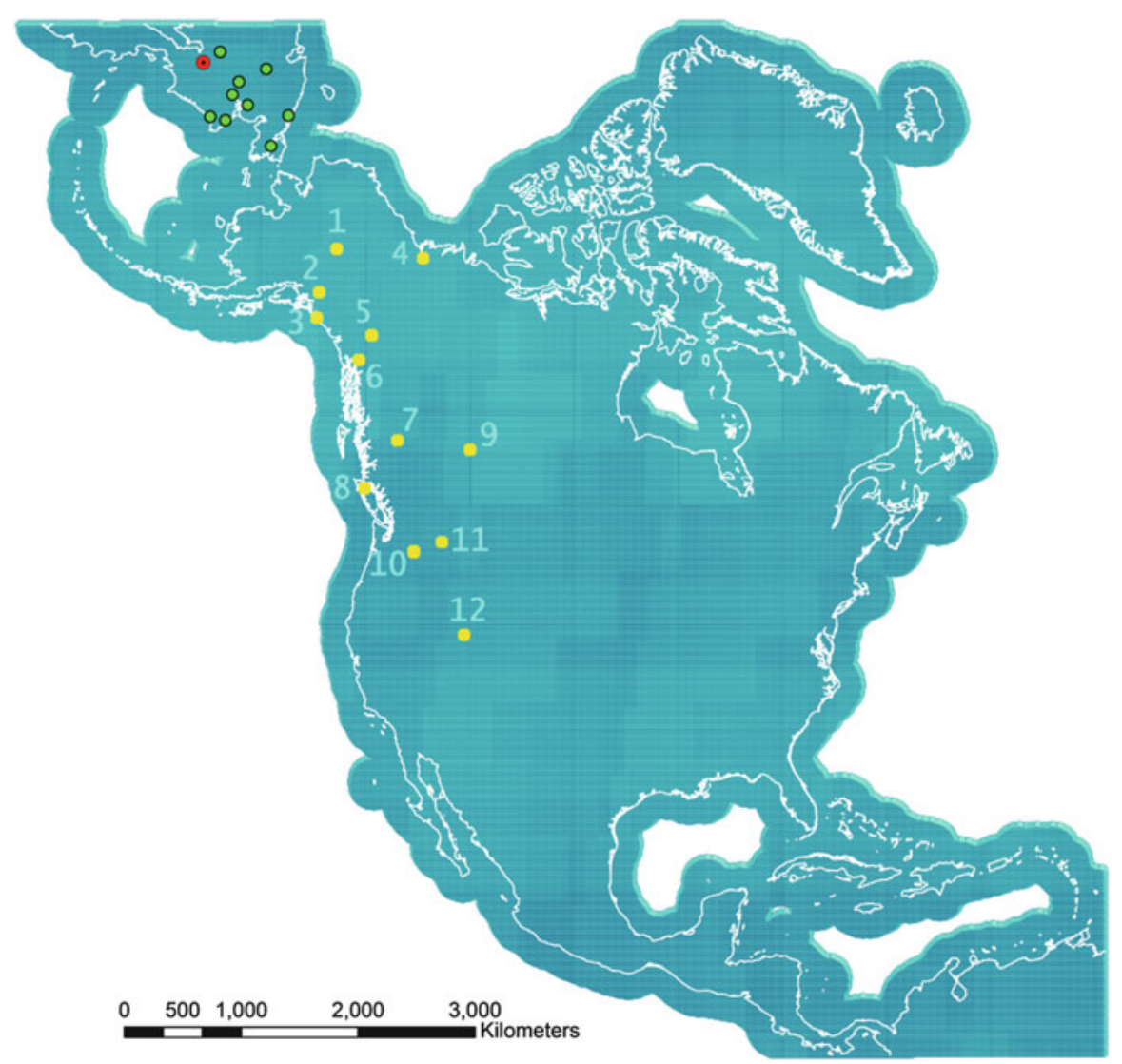

Fig. 17.1 Map of ABM arena showing 10-km grid of possible stopover points (blue), starting locations of uninfected agents (green), the population of disease origin (red), and 12 monitoring stations (yellow; numbered according to Table 17.2). Rendering the large number of stopover grid points at this scale has created an artificial distortion in the graphic 
To reduce processing time, we prepopulated properties for each grid point using data from underlying landscape characteristics maps (Fig. 17.2). These "static variables" included distance and direction to the closest ocean coastline, lakeshore, and river, as well as elevation, anthropogenic biome types, and human disturbance (Table 17.1A). We used these measures during the ABM simulations to allow individual agents to assess the stopover sites to inform avoidance, attraction, and settlement decisions when picking a stopover destination. We allowed certain metrics for each grid point to dynamically change during the simulations, which had implications for waterfowl agent stopover as well as HPAI transmission as the ABM progressed. These metrics included daily values of the total number of occupants, the number of diseased occupants, as well as the mean and standard deviation of disease virulence among infected occupants at each grid point (variables \#1 through \#4 in Table 17.1B; hereafter referenced in the format "Table 17.1B [1-4]"). Also tracked were individual agent metrics of status (alive and migrating), disease susceptibility, and the virulence and days of infection of any carried HPAI strain (Table 17.1B [5-9]).

At the outset of the ABM (i.e., "Day 0"), the total number of starting agents $\left(10^{6}\right)$ was equally distributed across ten hypothetical molting areas in eastern Siberia (Fig. 17.1). Our first introduction of variation into the simulation came during the disease seeding process when we allowed the ABM to (1) randomly choose the population where the disease originated; (2) randomly choose $\sim 10^{2}$ of the $10^{5}$ occupants (i.e., 0.001 probability for any individual) at that population to be infected; (3) randomly assign each individual's disease susceptibility, regardless of population or infection status (Table 17.1B [7]); (4) select an initial virulence for each diseased individual from a gamma distribution (Table 17.1B [8]); and (5) randomly choose each infected individual's preexisting day of infection from a gamma distribution (Table 17.1B [9]).

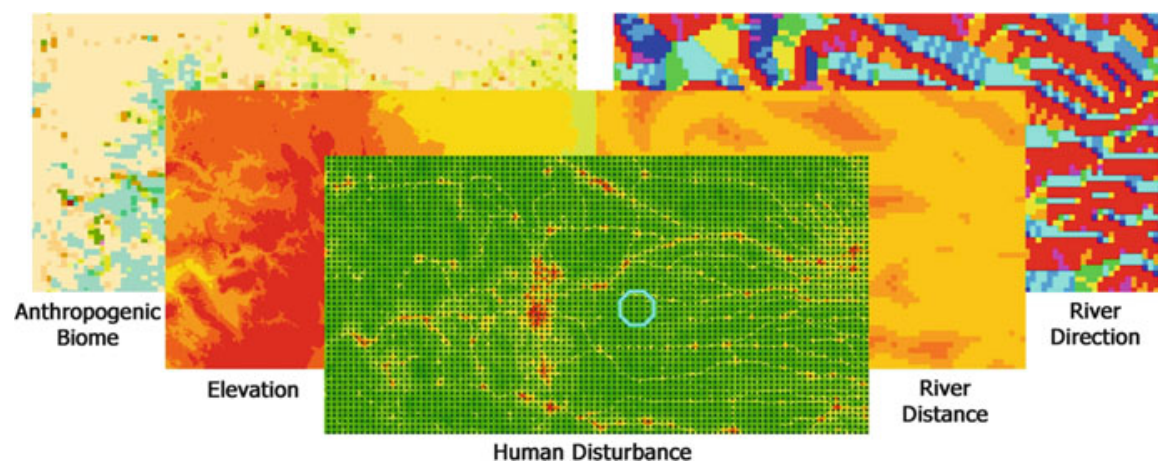

Fig. 17.2 Layer data embedded into each grid point in preparation for the ABM simulation. Shown atop the "Human Disturbance" layer is part of the 10-km grid of possible stopover locations as well as an example neighborhood (outlined in blue) within which an agent would probabilistically select its final stopover location based upon relative weightings of distance to water, human disturbance, and current density of agents 


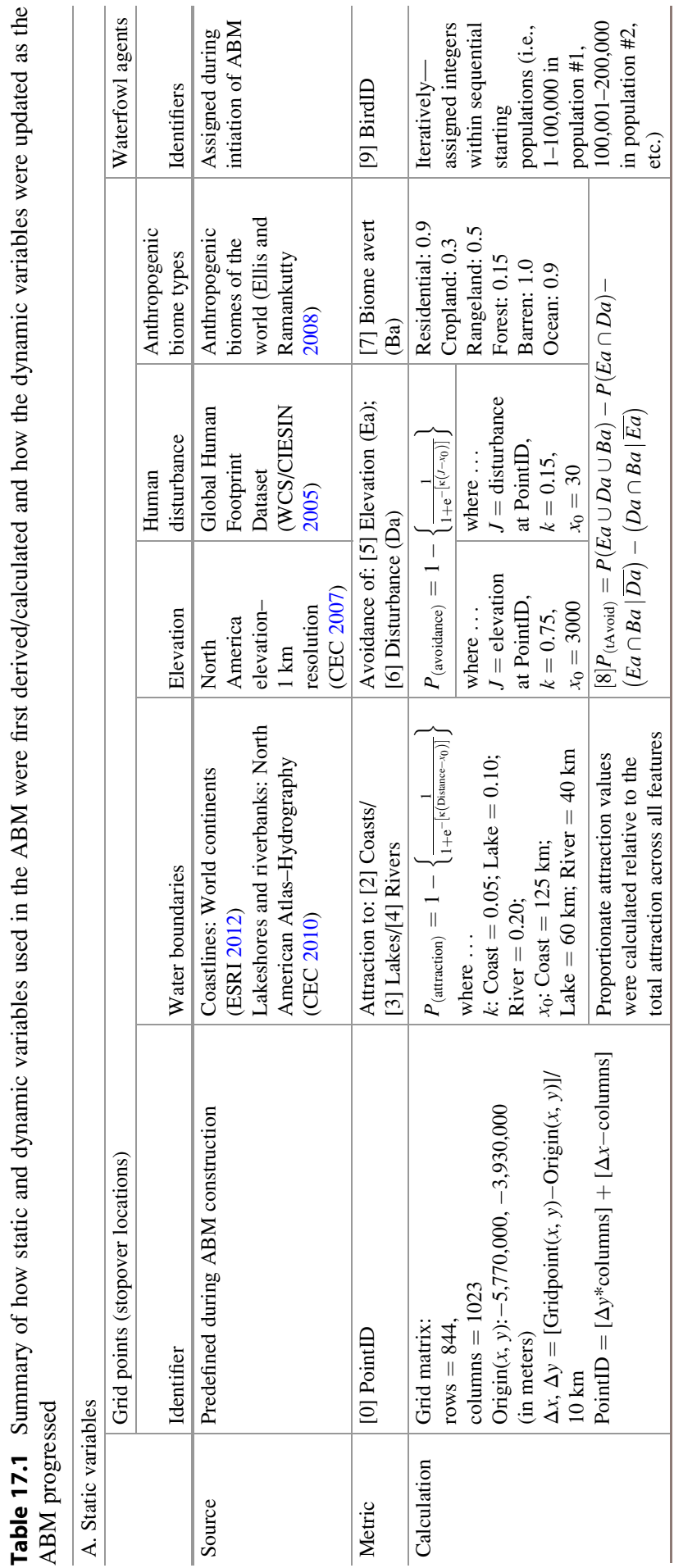




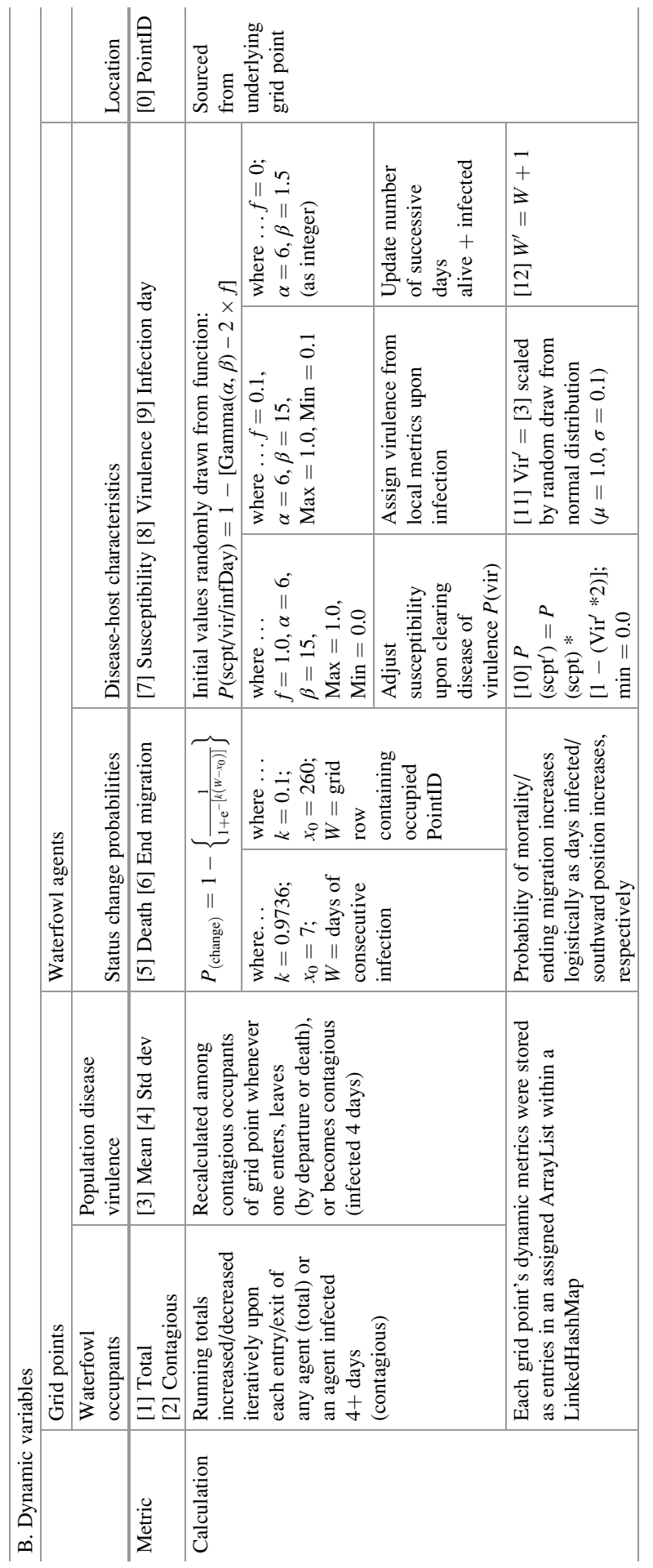




\subsection{Daily Disease Transmission, and Mortality}

At the outset of each new day, we programmed each uninfected individual to consult its current grid point metrics to determine the probability that it was exposed to a contagious agent (i.e., infection day $\geq 4$; Brown et al. 2008) given that each individual, regardless of disease status, was arbitrarily set to randomly experience exactly two density-independent interactions that would permit disease transmission with the other occupant(s) of the population (e.g., close feeding behaviors; Brown and Stallknecht 2008). If the agent was indeed exposed to a contagious individual, the probability that it contracted the disease was contingent on the susceptibility of the individual (Table 17.1B [7]) and, since the model did not account for which contagious agent was contacted, the mean and standard deviation of HPAI virulence at the population level (Table 17.1B [3,4]). Based upon a normal distribution centered on this population mean virulence and scaled by the accompanying population standard deviation, if a randomly drawn virulence value exceeded the inverse value of the individual agent's susceptibility, then we set the infection day of the agent to 1 . At the time of infection, the HPAI virus had the ability to mutate according to a normally distributed multiplier (Table 17.1B [11]). This meant that with every successful transmission, the HPAI strain could become more or less virulent but was most likely to remain unchanged (i.e., multiplier of 1.0). We constructed the ABM to thereafter determine if the agent would move to a new location.

Among waterfowl agents that were already diseased prior to the beginning of each day, we provided the opportunity to clear their HPAI strain or, failing that, we subjected these to an increasing probability of death prior to leaving their current location. Our ABM dictated the probability of clearing the HPAI infection according to three factors: (1) the virulence of the strain, (2) the susceptibility (i.e., inverse resistance) of the individual waterfowl agent to HPAI, and (3) a normally distributed multiplier with mean of 1.0 and standard deviation of 0.1 . If the virulence of the HPAI strain scaled by the random multiplier was less than the inverse susceptibility of the individual agent, we allowed the agent to clear the infection. When an HPAI strain was cleared, we adjusted the individual agent's susceptibility by a factor equivalent to the inverse of double the virulence of the strain being cleared (Table 17.1B [10]). In other words, if a strain with a virulence of 0.4 was cleared, the agent's susceptibility would be $20 \%$ of what it had been [i.e., $1-(0.4 \times 2)]$ and clearing a strain with virulence of 0.5 or greater imparted complete immunity upon the individual (i.e., new susceptibility $=0$ ). This would allow agents to possibly develop immunity to reinfection, especially if they cleared a particularly virulent strain of HPAI.

To simulate mortality in the population as a function of the day of infection, we used a logistic function (Table 17.1B [5]). This calculation meant that the probability of mortality rose with each subsequent day of infection, especially after the HPAI became communicable on Day 4. Yet, this function also meant that even noncontagious individuals had a modestly increased likelihood of death, which allowed us to ensure a background mortality among noninfected agents (i.e., infection day $=0$ ) 
equivalent to a $40 \%$ annual mortality in the absence of any disease (Franklin et al. 2002). If a randomly selected value between 0.0 and 1.0 fell below the infection day-based probability of mortality, we removed the agent from the simulation and, if it was infected, recorded upon its "death" the information about its HPAI strain's virulence (Table 17.1B [8 or 11]) and the number of sequential days it had been infected (Table 17.1B [9 or 12]).

\subsection{Daily Movements: Migration}

There were two types of possible daily movements that our ABM allowed: longdistance migration or neighborhood searches. The former, which we kept as relatively uncommon events (i.e., mean of 10-day stopover; Takekawa et al. 2010), led to the agent moving hundreds of kilometers in a semi-random fashion. If our ABM selected the agent to migrate, then we drew a random bearing from a normal distribution with mean $170^{\circ}$ and standard deviation of $60^{\circ}$ (Fig. 17.3). Because of our map projection, the real-world compass direction of movement changed as a function of geographic position; this meant that the agent would generally move in an eastern and then south-southeastern direction from its molting grounds to wintering grounds (see Fig. 17.1). We thereafter selected from a gamma distribution $[\gamma(\alpha, \beta) ; \alpha=6, \beta=0.015]$ a movement distance for the migrating agent. On the rare occasion that the selected value exceeded $1200 \mathrm{~km}$, we folded the

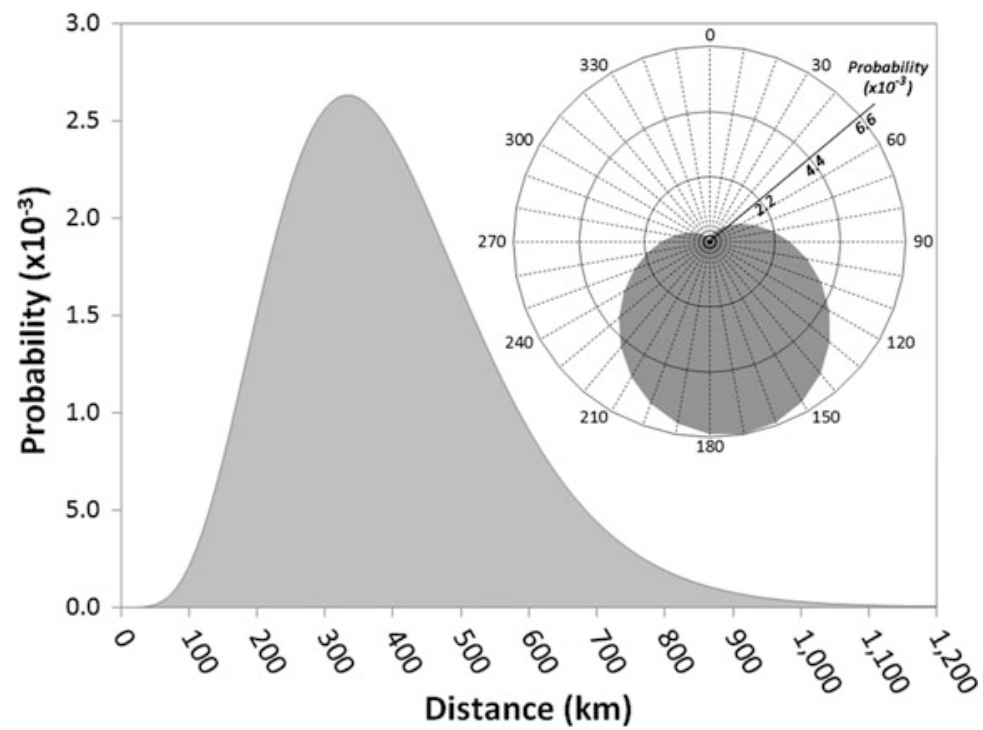

Fig. 17.3 Probability distributions for movement distances (base) and directions (inset) when agents migrated. Distance was calculated from a gamma distribution folded on itself beginning with distances above $1200 \mathrm{~km}$. Direction was drawn from a normal distribution with mean of $170^{\circ}$ and standard deviation of $60^{\circ}$ 
distribution back on itself [i.e., final distance $=(1200 \mathrm{~km}$-selected distance) $+1200 \mathrm{~km}]$ to prevent unrealistic travel distances (Fig. 17.3).

Prior to finalizing the movement of the agent, we programmed our ABM to check whether the proposed stopping point was valid (i.e., would land the agent within the arena and $\leq 200 \mathrm{~km}$ from land). If the movement was not valid, we set the model to pick a new migratory bearing and distance and recheck the validity of this new proposed movement. If a valid move could not be found after 100 attempts, we denied the agent the ability to migrate and, instead, relegated it to exploring its neighborhood for a more ideal location (see Sect. 2.4).

When an agent completed its migration, we set the ABM to relocate it to the nearest grid point and assess whether this was a sufficiently suitable stopover location. We based this site assessment upon a summation of logistic avoidance functions for elevation and human disturbance (Table 17.1A $[5,6]$ ), plus predetermined avoidance measures for anthropogenic biome type (Table 17.1A [7]). We then calculated the total probability of avoidance (tAvoid; Table 17.1A [8]) as the overlapping probability across all three factors (i.e., probability of avoiding any or all factors). If a random value drawn from 0.0 to 1.0 was less than tAvoid, then we forced the agent to move toward a nearby water feature (coastline, lake, or river) based upon the relative attraction of each from the current point. We determined the probability of displacement to one of the three alternative water feature boundaries using separate logistic functions of attraction for coastlines, lakes, and rivers (Table 17.1 A [2-4]). These values were each further adjusted by separate weightings for each water type that we had predefined in the model: in our case, 0.2, 0.8, and 0.5, respectively. We then scaled the relative attraction to each water type against the total draw across all three water types, and the resulting value was used to define successive bins of probable relocation to each water type. Based upon which bin contained a random number drawn between 0.0 and 1.0 , we selected the associated nearby water boundary to relocate the agent.

\subsection{Daily Movements: Neighborhood Exploration}

At either the end of the migratory jump and possible relocation or, if the agent did not migrate, at the original point, we allowed the agent to explore its neighborhood for a "more suitable" location. We defined a neighborhood as the agent's current location plus all surrounding grid points within $25 \mathrm{~km}(n=20$, unless any grid points fell outside the $200 \mathrm{~km}$ coastline buffer or the ABM arena; Fig. 17.2). We determined the relative attractiveness of the neighborhood grid points (RelBWwt) based upon a combination of avoidance of human disturbance (Da; Table 17.1A [6]) and the maximum attraction to coast, lake, or river (maxWA; Table 17.1A [2-4]), as well as the total agent occupants (tOcc; Table 17.1B [1]) relative to a predefined optimum (OptD): in our case arbitrarily set at 1500 agents/grid point. In each case, we defined an adjustment factor so that the weighting of each variable could be given more or less importance (" $b$ " for Da, " $w$ " for maxWA, " $q$ " for tOcc). The RelBWwt value was precalculated for each grid point as: 


$$
\text { RelBWwt }=\frac{\left[\left(-\mathrm{Da}^{*} b\right)+\left(\operatorname{maxWA}{ }^{*} w\right)\right]}{b+w+q}
$$

Since tOcc was a dynamic value, this required recalculation each day. We also used a slope factor $(f)$ to more strongly weight tOcc as it approached OptD. We did this so that density could vary more in its influence over how agents selected the optimal point in the neighborhood. The resulting formula for density weight (DENSwt) was:

$$
\text { DENSwt }=\left\{1 /\left[\frac{|\mathrm{tOcc}-\mathrm{OptD}|}{\mathrm{OptD} f^{-1}}+1\right]\right\}^{*} q
$$

The sum of DENSwt and RelBWwt provided a total weight for the grid point, which we then scaled against the cumulative weight across all neighborhood grid points to determine a relative bin size. We designated bins according to each one's sequential position in the neighborhood, and using a random draw from a uniform distribution between 0.0 and 1.0, we selected the agent's new point based upon the bin in which this number fell.

Once a grid point was selected, we moved the agent to its new position and accounted for it within the dynamic grid point metrics (Table 17.1B [1-4]). Regardless of disease infection, we added every incoming agent to the tOcc tally. We likewise added individuals diseased at least 4 days to the tally of occupants likely to be contagious (cOcc; Brown et al. 2008) and then calculated a new mean and standard deviation for HPAI virulence across all of the strains infecting contagious individuals. We ensured that these new values for each metric could only be consulted in the subsequent day and retained the day's starting values so that all subsequent disease transmission and migratory movements among the remaining agents would remain unbiased. In this way, movement of a contagious agent into a new population would not result in added probability of disease exposure at this new location until the next day.

At the end of each simulated day, we recorded the total number of HPAIinfected, contagious, and dead individual agents so that we could track the overall disease dynamics throughout the entire simulation arena. We likewise recorded on each day the status of each agent in terms of being alive and/or in a migratory state, its current grid point position (Table 17.1B [0]), its susceptibility to HPAI, as well as metrics of its HPAI infection: day of infection and virulence of the strain (zeros if not infected; Table 17.1B [7-12], where applicable). For each grid point we also logged daily metrics, including number of occupants, number of contagious occupants, and the mean and standard deviation of virulence across all HPAI strains present (Table 17.1B [1-4]. Across the entire 90-day study period, we tracked the distribution of all agents - as well as the subset of contagious agents-relative to the location of the disease origin, in this case: N62.703, W167.117 (red dot in Fig. 17.1). We calculated the median, quartile, and maximum distances among these two groupings at 6-day intervals during the study period and determined the day by which each measure exceeded the minimum distance from the origin of the 
disease to the contiguous USA $(4200 \mathrm{~km})$. These latter calculations were intended to estimate how quickly the agents and the disease, respectively, could have possibly reached population centers in the contiguous USA.

\subsection{Simulating Monitoring Effort}

To evaluate on-the-ground monitoring of disease connectivity, we established a simulated network of monitoring stations at twelve grid points that were located at potentially favorable stopover locations (i.e., relatively low-altitude lakes with little human disturbance within $50 \mathrm{~km}$ of human settlements; Fig. 17.1). We allowed the stations to sample daily within a $12.5 \mathrm{~km}$ radius of the station (i.e., a $3 \times 3$ block of grid points) for signs of communicable HPAI in the agents present. Early-infected agents that were not yet contagious were considered undetectable (i.e., asymptomatic during Days 1-3). To roughly account for density-dependent sampling coverage, we calculated the daily probability of disease detection $[P(\mathrm{dd})]$ using the $\log _{10}$ value of tOcc as the base of a root function for the proportion of cOcc in the population:

$$
P(\mathrm{dd})=\sqrt[\log _{10} 0_{\mathrm{toc}}]{\frac{\mathrm{cOcc}}{\mathrm{tOcc}}}
$$

This calculation allowed for contagious individuals to experience a higher rate of detection, especially within smaller populations (Brown and Stallknecht 2008). To increase random effects into the probability of disease detection, we then multiplied the resulting value by a normally distributed chance factor with mean of 1.0 and standard deviation of 0.25 . If this adjusted detection probability was lower than a random number drawn from a uniform distribution between 0.0 and 1.0, then we determined that HPAI had been detected at this location. We repeated this process 99 more times, each time drawing new chance and random factors. Across all of these repetitions, we then were able to calculate an overall probability of a single detection at each site on each day as the proportion of iterations that produced a positive detection. We likewise calculated the probability of a single detection across any station in the monitoring network. We further calculated the probability of detecting at least one additional contagious agent within a 3-day window (i.e., a "confirming detection"). We calculated this probability separately at each site, as well as collectively across sites, the latter representing a network of stations that would be sharing real-time updates of HPAI detections. This assumed that diagnosis and reporting of the disease could be accomplished in a single day, which may be a departure from reality depending on the testing protocols required.

On the day of migration when the site or network had an $80 \%$ or greater probability of detecting HPAI (i.e., a "likely detection"), we determined how far the disease had already spread past the monitoring station, as well as the slope of the 1-day change in the contagious/symptomatic proportion of the surviving population (i.e., the "apparent infection rate"; Van Der Plank 1963). For the former, we 
calculated this based upon the abundance and relative proportion of still-alive agents that were contagious and located between $215^{\circ}$ and $90^{\circ}$ from the sampling point (i.e., "escapees"). Among escapees we calculated the mean and median distance from the sampling station, as well as the mean HPAI virulence among contagious agents. In terms of the apparent infection rate occurring at the time of likely detection, we calculated that value based upon the daily change in the proportion of the still-alive population that were contagious, since these were the only diseased individuals that were symptomatic (hence, "apparent"). We then independently assessed the efficacy of each of the 12 sampling locations to detect a disease during the early stages of the disease outbreak and then repeated these same calculations using data based upon 3-day confirming detections. Complete ABM code used within Agent Analyst/RePast available at: https://github.com/ rossjd/Migration_monitoring_ABM.

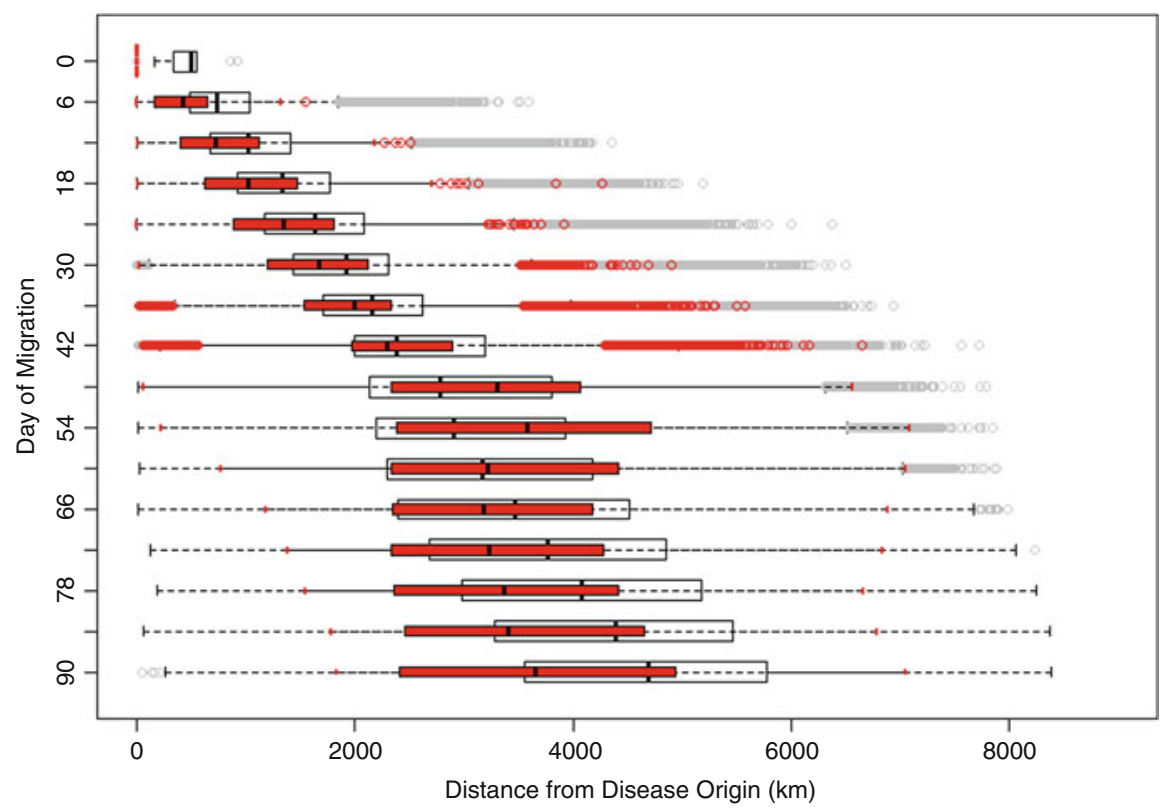

Fig. 17.4 Boxplot distributions of distance from the Siberian population of disease origin among both total occupants (white bars-grey circles) and contagious occupants (red bars and circles) over 6-day intervals of the study period. Note the descending scale on the $y$-axis 

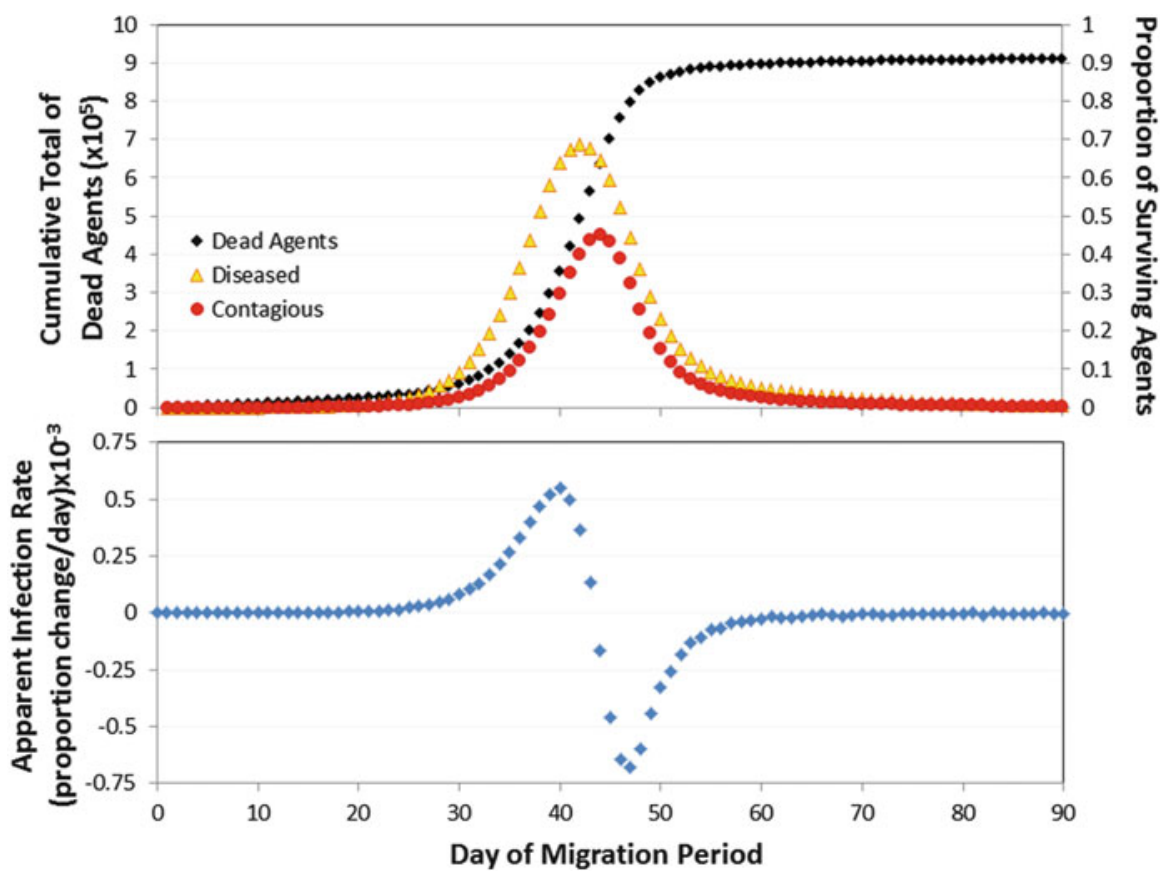

Fig. 17.5 Disease prevalence, infection rates, and mortality metrics across the entire study arena during the ABM-simulated study period. Cumulative numbers of dead agents (black diamonds) are plotted along the upper-left axis, proportions of surviving agents that were diseased (orange triangles) or contagious (red circles) are plotted along the upper-right axis, and day-to-day changes in the proportion of contagious agents (i.e., the apparent infection rate) are plotted in the lower panel (blue diamonds). The $x$-axis is consistent for both panels

\section{$3 \quad$ Results}

\subsection{Breeding-to-Wintering Ground Connectivity}

Displacement data, measured as the minimum Great circle route distance over land or ocean from the disease origin, indicated a relatively constant migration and spread of the entire agent population throughout the 90-day simulation period (Fig. 17.4). These patterns were evident as a linear increase of the median distance (black bars within white boxplots in Fig. 17.4) and progressively higher variation within the data (i.e., wider boxplots), respectively. The distribution of contagious individuals, however, appeared to show a different and less-consistent pattern of spread. Specifically, the midpoint of contagious individual locations appeared to spread rapidly outward between Days 42 and 48, which corresponded to the period of rapid collapse in the disease outbreak (Figs. 17.4 and 17.5). The relative distribution of contagious individuals then appeared to largely stagnate, as the 


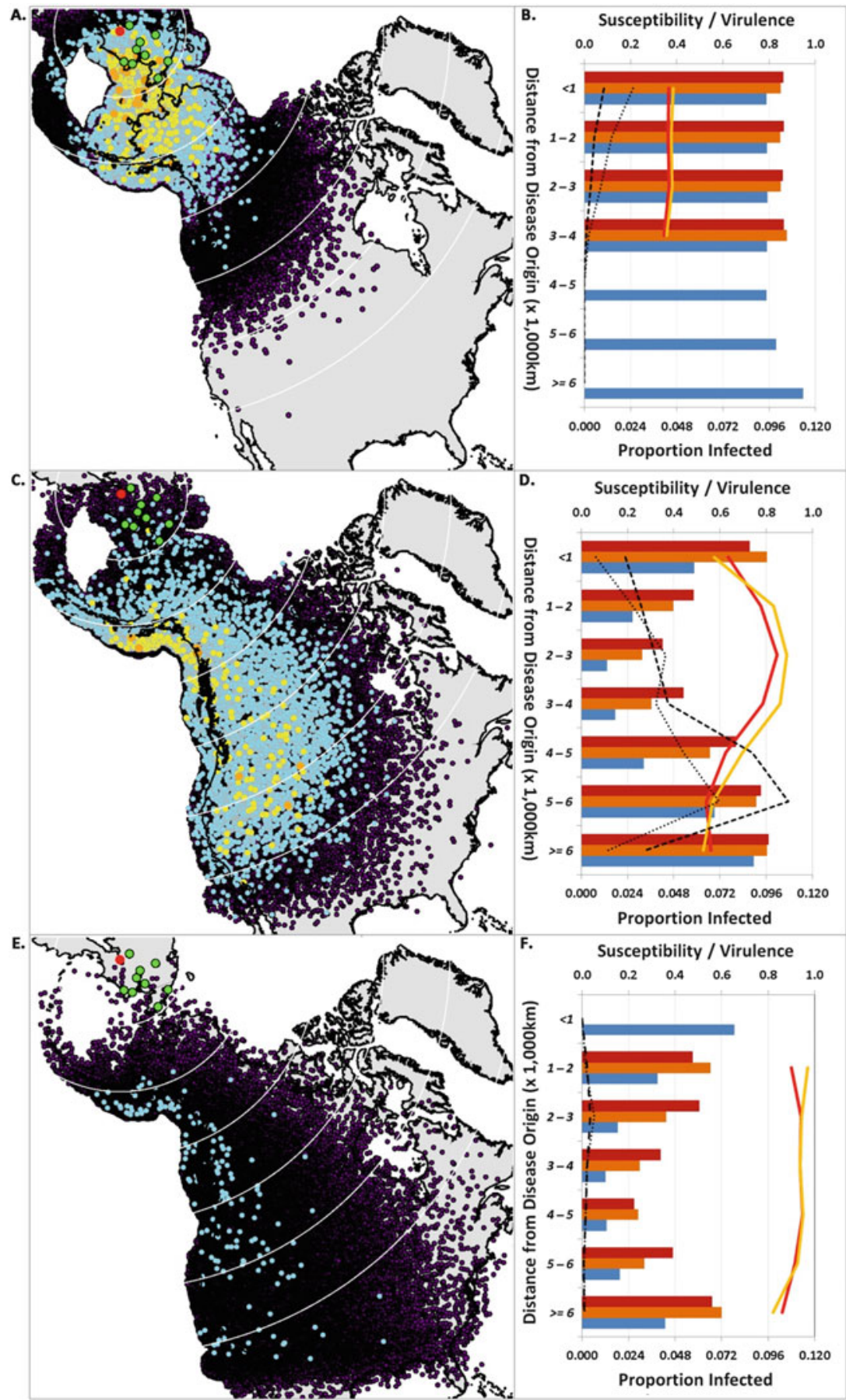

Fig. 17.6 Shifts in spatial distribution of agents (left panels) and disease prevalence/virulence and host susceptibility (right panels) over three select days: (a, b) Day 23-confirming detection by monitoring network; (c, d) Day 54-latest day of independent disease confirmation at a 
median displacement distance remained between 3300 and $3550 \mathrm{~km}$ from Day 48 onward (Fig. 17.3). These distances correspond to approximately northwestern Canada, while the central quartiles during this same time period corresponded to approximately eastern Alaska through western Canada and the Pacific Northwest of the United States (i.e., 2500 and $5000 \mathrm{~km}$ from the disease origin; Figs. 17.1 and 17.6).

Cumulative migratory displacements long enough to have reached the contiguous United States ( 4200 km from the disease origin) were first observed among a handful of agents by Day 12 of the period; though the second quartile of total survivors did not reach this distance until Day 66 and their median distance did not exceed this distance until after Day 84 (Fig. 17.4). Among contagious agents, the total distance of travel first exceeded $4200 \mathrm{~km}$ by Day 18, although this was only one individual. It was not until Day 30 that additional diseased individuals had progressed far enough to possibly reach the contiguous United States (Fig. 17.4). Following the rapid geographic shift in symptomatic agent displacement distances after Day 42, the second quartile of surviving contagious agents overlapped $4200 \mathrm{~km}$ by Day 54 . Though these agents were still able to normally migrate, the sudden shift in the distribution was more likely attributable to massive die-offs of diseased agents at locations closer to the HPAI outbreak origin than to an uptick in daily migration distances among diseased agents. The median distance of displacement from the HPAI origin site among symptomatic agents never exceed $4200 \mathrm{~km}$; therefore, by Day 90 the bulk of the contagious population could have never reached the contiguous United States under this simulated scenario. However, there were certainly many instances of symptomatic individuals appearing well within that area (Fig. 17.6c), which could have been sufficient to infect resident wild bird, domestic fowl, or even human populations.

\subsection{Disease Monitoring}

Networked Stations Using a 12-station network of monitoring stations throughout northwestern North America, our model detected with a $\geq 80 \%$ probability the first contagious agent on Day 18 of the migration period. By this point: only 0.16 and $0.56 \%$ of the surviving population were contagious or at least infected, respectively.

Fig. 17.6 (continued) monitoring station; and (e, f) Day 90-last day of simulation period. Lefthand maps indicate: $1000 \mathrm{~km}$ distance intervals (white rings) from disease origin (red dot); locations of uninfected agents (purple points), infected agents (in increasing abundance: blue, yellow, and orange points), and starting populations of the nine uninfected populations (green dots). Right-hand panels summarize within $1000 \mathrm{~km}$ distance bins from Siberian disease origin: proportionate abundance and mean disease virulence among contagious (dashed black and red lines, respectively) and early-infected agents (dotted black and orange lines, respectively), and mean susceptibility among contagious (red bars), early-infected (orange bars), and uninfected agents (blue bars) 


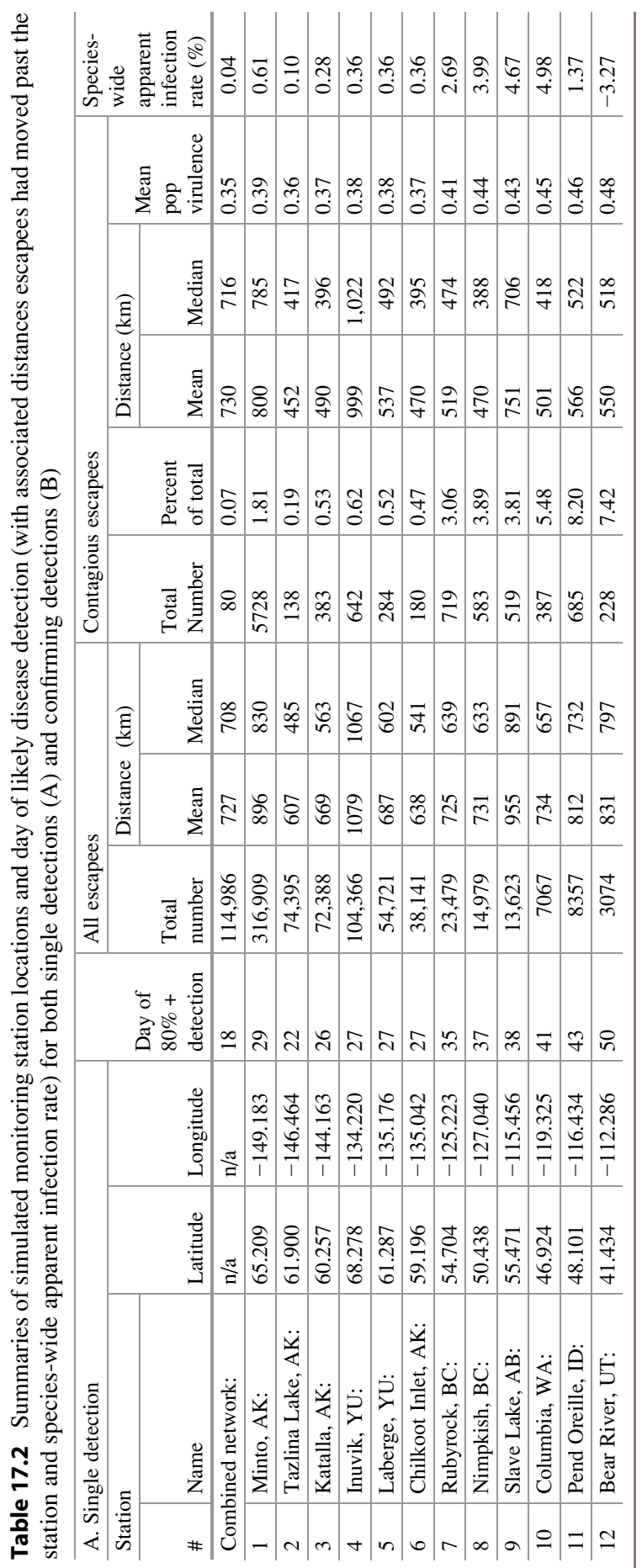




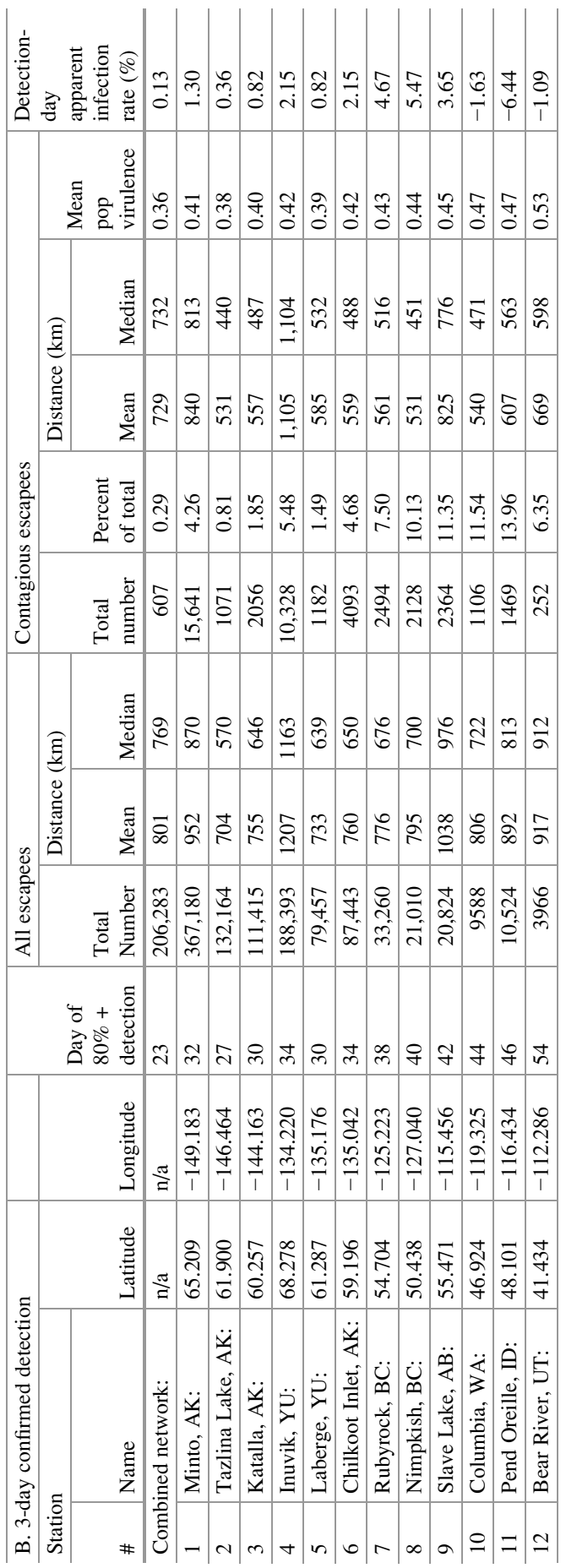


Furthermore, only 80 contagious agents ( $0.07 \%$ of survivors) had escaped beyond any monitoring station by this day, although one symptomatic individual had already reached a point $2320 \mathrm{~km}$ ESE past the northwestern-most monitoring station (Minto, AK) and diseased escapees were located an average of $730 \mathrm{~km}$ from that station. The mean virulence among strains that had passed at least one monitoring station by Day 18 remained relatively low at 0.35 (Table 17.2A).

If at least one more confirming detection of the disease within a 3-day period was required, then the network of stations was $\geq 80 \%$ likely to confirm the disease by Day 23. By this point, 0.56 and $2.02 \%$ of the surviving population were contagious or at least infected, respectively, and 607 contagious individuals $(0.29 \%$ of survivors) were already present beyond at least one monitoring station. Interestingly, contagious individuals were spread similarly to Day 18, with the furthest present $2042 \mathrm{~km}$ SSE from Minto, AK, diseased escapees located an average of $729 \mathrm{~km}$ beyond that station, and mean virulence remained relatively low at 0.36 (Table 17.2B). Most of the contagious agents were still contained within or near Siberia or Alaska on Day 23 and the bulk of diseased individuals appeared to be centered on the Bering Strait area (Fig. 17.6a).

Individual Stations Under the scenario of independently operating stations, the rapidity of detecting the disease was understandably lower than if the stations were in constant communication as a network. Certain stations appeared to be more likely to detect the disease than others in the vicinity, particularly in Alaska where the station closest to the Siberian disease origin (Minto, AK) was slower to detect or confirm the outbreak (Days 29 and 32, respectively) than locations further south and east (Table 17.2). This would have meant that this station wouldn't have reported the outbreak until it was well into the acceleration period (i.e., apparent infection rate rising by $0.61-1.30 \%$ per day, depending on detection criteria). In contrast, the nearest station to Minto, AK-located only $400 \mathrm{~km}$ SSE at Tazlina Lake, AKrapidly detected the disease outbreak and appeared to do so at an early stage of disease acceleration (i.e., apparent infection rate was rising at only $0.10-0.36 \%$ per day, depending on detection criteria; Table 17.2). The primary difference between these stations was that Minto, AK, is located far inland (W of Fairbanks) while Tazlina Lake, AK, is nearer the coastline (NE of Anchorage; Fig. 17.1). Within the structure of the ABM, these characteristics could have favored greater amounts of traffic near the latter station, which would have promoted greater probability of disease transmission within increasingly dense stopover populations.

Across all stations, there was a strong positive correlation between the distance from the disease origin in Siberia (N62.703, W167.117) and the day of earliest disease detection, regardless of detection criteria $\left(R^{2}=0.92\right.$ for either single or confirming detections; Fig. 17.7). This would be consistent with the disease being propagated relatively evenly across a broad front that progressed, on average, between 135 and $145 \mathrm{~km}$ per day (calculated from regression slopes for single and confirming detections, respectively). This rate of disease travel is very unlikely to be simply mediated by individual movements when one considers that (1) the migrations of individual waterfowl agents were set to occur on average every 


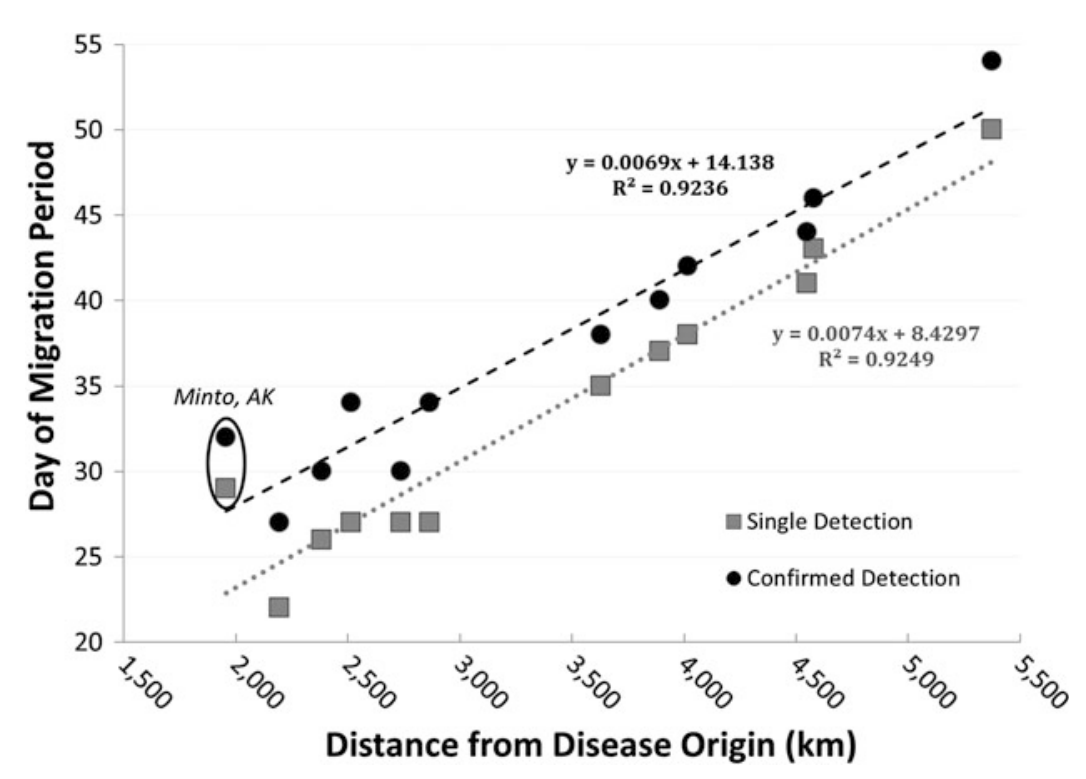

Fig. 17.7 Linear relationship between the distance of monitoring stations from the Siberian disease origin ( $x$-axis) and the day of $\geq 80 \%$-probable disease detection (inverted $y$-axis) for both single detections (grey squares) and confirming detections (black circles). Data from Minto, AK, are circled to illustrate their relative displacement above the regression line, which indicates that disease detections were made at this site later than expected given the proximity of the site to the disease origin

10 days, (2) those movements were selected from a gamma distribution that peaked at $\sim 330 \mathrm{~km}$ and was restricted to a maximum of $1200 \mathrm{~km}$ (Fig. 17.3), and (3) the probability of mortality quickly rose as a function of the number of days infected. Instead, the most parsimonious explanation is that disease transmission occurred across a series of individuals that were newly infected at successive stopover sites. This aligns with Gaidet et al.'s (2010) similar conclusions which were drawn from actual satellite tracking data among East Asian migratory waterfowl.

\subsection{Evolution of Disease Virulence and Host Susceptibility}

Much as there was a strong correlation between the distances from the Siberian HPAI origin to each monitoring station versus the days of disease detection, there was also a strong positive correlation between the latter and the mean HPAI virulence among agents that had escaped past each monitoring station. Based upon a linear regression of these data, we found that HPAI virulence appeared to consistently rise over time by a factor of $+0.005 /$ day (data not shown). This increase in virulence among surviving HPAI strains effectively reflects the iterative selection pressure imposed on the virus over successive stages of mutation and selection and is likely the result of the following aspects of our ABM: (1) waterfowl 
hosts can develop resistance through exposure and recovery from less-virulent HPAI strains; (2) clearing the infection is a function of susceptibility and the virulence of the present HPAI strain; and (3) the probability of mortality quickly rises as a function of the number of days an agent has been infected.

The increase in mean virulence was not restricted to only those agents that escaped beyond a given monitoring station; by the time the disease was confirmed at the last station (Day 54 at Bear River NWR, UT; Table 17.2), the mean virulence across the 5686 agents contagious on that day was 0.720 and across 4739 earlyinfected but asymptomatic agents the mean virulence was 0.799 . At the outset of the simulation, 112 of $10^{6}$ agents had been infected with HPAI strains that had a collective mean virulence of only 0.227 .

Reflecting the simulated evolutionary arms race incorporated into the $\mathrm{ABM}$, the HPAI susceptibility of surviving agents likewise shifted during the simulation; that is, agents with increasingly lower susceptibility tended to resist the increasingly more virulent strains. At the outset of the simulation (Day 0), the mean susceptibility across all $10^{6}$ agents had been 0.793 . By Day 54 , the mean susceptibility had fallen to 0.210 among uninfected agents $(n=101,916), 0.404$ among early-infected agents $(n=4739)$, and 0.536 among contagious agents $(n=5686)$. Among the agents dead by Day 54, 821,658 had died while contagious, 27,232 had died when early infected (Days 1-3), and 38,768 had died without infection (i.e., natural background mortality).

Sticking with the example of Day 54, our examination of locations of diseased agents indicated a dispersed distribution along the Pacific Coast and Rocky Mountain region of North America (Fig. 17.6c). However, when we examined the mean values of HPAI virulence and susceptibility across this area, we found that individuals within a band $2000-3000 \mathrm{~km}$ from the disease origin possessed quite virulent strains of the disease, which was counterbalanced by very low susceptibility-especially among uninfected individuals (Fig. 17.6d). At the leading edge of the disease spread (i.e., $\geq 5000 \mathrm{~km}$ from HPAI origin), mean susceptibility was high among all agents, regardless of infection status, which indicates that neither natural selection on hosts for high resistance nor a widespread acquisition of immunity had greatly impacted those populations by Day 54. Across all but the smallest $1000 \mathrm{~km}$ bins, a consistent pattern was observed for mean susceptibility-that contagious, then early-infected, and then uninfected agents showed stepwise decreases in their levels of susceptibility to HPAI (re)infection. This appeared to fit within the construct of our ABM, wherein the host's susceptibility is roughly proportional to the inverse probability of clearing an infection (hence the higher susceptibility among contagious agents) as well as the probability of being infected after exposure (hence the elevated rate among early-infected agents relative to the uninfected pool).

By the end of our simulation period on Day 90, the suppression of susceptibility remained, though it had shifted further away from the disease origin and peaked at the 4000-5000 km range (Fig. 17.6f). Mean virulence had risen to very high levels across the arena, though the proportion of agents that were diseased had fallen to very low levels. At the end of the simulation period, the original population of one 
million agents had been reduced to 90,615 . This is a very high mortality rate and, as such, may point to the present ABM as a "worst-case scenario" for the emergence and pathology of the simulated HPAI strain. Of the remaining agents, 14,395 had ceased migration at rather broadly spaced wintering locations generally in the mid-continental USA (i.e., beyond $6000 \mathrm{~km}$ from the disease origin; Fig. 17.6e). The mean virulence and susceptibility among the few infected wintering agents, either contagious ( $n=19)$ or not $(n=20)$, was 0.810 and 0.619 , respectively. Mean susceptibility among uninfected wintering agents, although relatively low at 0.362 , had not dropped to the levels seen in areas where the disease had been more prevalent (i.e., $3000-5000 \mathrm{~km}$ from the origin; Fig. 17.6).

\section{Discussion}

The exercise we have presented in this chapter was aimed at the general topic of tracking large-scale connectivity among individual animals, and the diseases they carry, as they actively move through the aerosphere to traverse vast landscapes. The ABM used in our theoretical scenario is broadly based upon generalized waterfowl biology, including migration behaviors, conspecific attraction, landscape usage, and HPAI transmission dynamics. Though flight-driven connectivity clearly has the possibility to influence evolutionary and ecological processes related to the species itself, such point-to-point links can drive other ecological processes such as the transfer of energy, nutrients, parasites, or diseases.

A realistically parameterized agent-based model can allow the study of different aspects of natural processes, such as bird migration or disease transmission, perhaps even using the same simulation output in a similar fashion to how scientists of various disciplines could each study different aspects of a natural system. A major advantage of the ABM simulation framework is that we may readily alter input parameters independently, which allows for sensitivity analyses regarding how each factor might disproportionately affect the model output—something that is not easily achieved or even possible under natural or rare circumstances. Even in cases where the input parameters used in $\mathrm{ABMs}$ are approximations or generalizations, such as in our case, the scenario evaluations possible through individual-based modeling can still provide valuable biological insights that can inform further data collection, modeling, or management planning (MacPherson and Gras 2016).

\subsection{Simulating Migratory Connectivity: Biological Insights}

Movement through the aerosphere using powered flight is the fastest way that vertebrate animals can naturally traverse large geographic distances (Alerstam 2003, 2011), allowing for transcontinental transmission of biomass over relatively short periods of time. In the example presented in this chapter, the simulated migration of one million generalized waterfowl from Siberia to the southern USA 
occurred in some cases within 3-4 weeks. Such rapid movements are not unusual among migratory bird species (Fuller et al. 1998; Kjellén et al. 2001; Alerstam 2003), especially waterfowl (Green et al. 2002; Gaidet et al. 2010; Prosser et al. 2011), though cross-continental, longitudinal movements of individual land birds remain only sparsely studied (e.g., Bairlein et al. 2012).

Long-distance migration facilitated the spread of our simulated highly pathogenic virus. However, migration of the simulated waterfowl host was not in complete lockstep with the dispersal of the HPAI outbreak. In part, this was because of the time required for an HPAI outbreak to achieve critical mass and partly because of apparent selective forces acting on both host and virus. With respect to the former, our model indicated that communicable agents remained rare and the mean virulence of HPAI strains they carried remained relatively low during the first 18 simulated days (Fig. 17.4), by which time nearly half of the total population had moved beyond Siberia (i.e., displacements $>1100 \mathrm{~km}$ ). Even by Day 23, when the disease had spread across Alaska and had been confirmed by the simulated monitoring network, the mean virulence of the disease remained modest (Table 17.2B), although sufficient to readily infect the still quite-susceptible population of agents (Fig. 17.6b).

Subsequent to Day 23, when the HPAI became rapidly more pathogenic and prevalent, the rampant buildup of diseased occupants corresponded to widespread mortality that ultimately resulted in the death of $>90 \%$ of the entire agent population (Fig. 17.5). A high proportion of surviving agents at distances $>4000 \mathrm{~km}$ from the disease origin were contagious by Day 54 (7.5\%; Fig. 17.6d), which suggests that the virus had disproportionately spread outward during the outbreak phase. The median location of uninfected birds likewise continuously progressed further from the disease origin (Fig. 17.4). However, at no point in our simulation did the median distance of contagious individuals from the disease origin spread exceed $3600 \mathrm{~km}$. In effect, the center point of the disease population appeared to stall after being transmitted only part of the way to wintering grounds. This supports the interesting possibility that migration might initially help but eventually hinder the spread of disease (Altizer et al. 2011), especially when it comes to the geographic extent of HPAI spread (Lam et al. 2012). Such data could only be gleaned from studying the individual interactions between disease and host (Morales et al. 2010) and are an improvement upon well-founded but limited models of disease spread based on very coarse-scale range maps and movements (e.g., Peterson et al. 2009).

The apparent selective interactions in our ABM between host and disease seem to have driven another interesting dynamic-that the surviving populations emerged with greatly elevated levels of resistance (inverse susceptibility) or virulence, respectively. Since we had simulated only a single-species host for HPAI, this meant that equilibrium was eventually reached and the disease returned to relatively low incidence among the surviving hosts (Figs. 17.5 and 17.6). In this respect, the HPAI population had been distilled down to nearly its most potent form (i.e., virulence $=1.0$ ) as a result of selective feedback during stepwise migratory jumps. One may predict that possible alternative hosts for HPAI encountered at points further south could be quite susceptible to such a highly virulent strain of the 
disease. Such a situation could present a serious risk of rapid infection and widespread mortality in these new hosts, even if there was some degree of native HPAI resistance present. From a competitive standpoint, this could give migratory species an evolutionary advantage on wintering grounds. From an economic standpoint, this could mean that transmission of this HPAI strain into domestic stocks could bring widespread devastation. Such scenarios are possible and warrant further examination using $\mathrm{ABMs}$ which incorporate data from targeted quantification studies, such as challenge assays of susceptibility, exposure, infection, and recovery/clearance (Pantin-Jackwood et al. 2007; Brown et al. 2006, 2008).

\subsection{ABM-Informed Disease Monitoring and Mitigation}

Of significant human health and economic concern is whether confirmed disease detections could be made early enough during an outbreak to prevent further spread and allow effective mitigation efforts within already infected populations (Brown and Stallknecht 2008). Since asymptomatic carriers (e.g., early-infected or resistant individuals) might fly through the aerosphere rapidly and with fewer barriers, the efficacy of a disease monitoring and mitigation program could be drastically altered by delays of just a matter of days (DeLiberto et al. 2011). In our example, the twelve hypothetical monitoring stations distributed from Alaska to Utah varied widely in how quickly they were likely to detect the disease. This pattern was driven almost entirely by the station's distance from the disease origin. However, in the case of the station at Minto, AK, detection and confirmation of the disease lagged far behind the nearest station, Tazlina Lake, AK, despite the former being located closest to the disease origin (Fig. 17.1). The comparative delay of 5 (single detection) to 7 days (confirmed detection; Table 17.2; Fig. 17.7) meant that by the time the disease would have been independently reported at the Minto station, AK, the disease was well into an outbreak, with apparent infection rates 6.2 to $3.6 \times$ higher (respectively) than when HPAI was detected at Tazlina Lake (Table 17.2 and Fig. 17.5). Losing this amount of time during the critical early stages of an HPAI outbreak is likely to undermine the efficacy of subsequent mitigation efforts to stem further disease spread (Brown and Stallknecht 2008). Under this scenario, the resources allocated to the Minto monitoring station, AK, would have been much more effective at other sites, such as closer to coastal waterways where the agents appeared to accumulate (Fig. 17.6).

A communicating network of monitoring stations certainly improved the ability to monitor for detectable symptoms of a disease outbreak, though with the caveat that disease detection and information sharing were both instantaneous. Not surprisingly, we found that the early warning efficacy of the network was driven by data generated at only one or two stations in Alaska. Depending on our confidence in the parameters of the model, we could be inclined to say that prioritization of resources should be given to these stations if we wanted to maximize our probability of detecting and confirming a disease during the earliest stages of an outbreak. 
However, by reducing the geographic spread of monitoring stations, agencies would have limited capacity to track HPAI dynamics over the course of its invasion of North America. We saw from our simulation that the bulk of the disease outbreak never progressed much beyond Canada. However, our model also indicated that the HPAI achieved a very high level of virulence along the migratory route. Tracing such patterns so that the impending outcome can be more accurately predicted could be critical to avoid an over- or understatement of risk. Such inaccuracies could undermine regulatory agencies' ability to elicit public responses in the face of subsequent disease threats, especially as it pertains to reducing potential avenues of host switching into humans.

\subsection{Field Testing and Applying ABMs}

Field monitoring is important as a way to continually refine predictive models, as well as to validate the predictions being made in those same models. Such on-theground efforts may also be the most effective way to monitor migratory populations for evidence of communicable diseases, in particular those of potential human economic or health impact such as avian influenza (Wobeser 2013). Our model made relatively static assumptions regarding the detectability of contagious individuals relative to asymptomatic or uninfected individuals and that detectability would increasingly rise in smaller populations. However, human observers would likely have much greater intuition about changes in the norm at their sites and could provide the capacity to rapidly adjust monitoring efforts in the face of an emerging disease outbreak. In turn, they could benefit from ABM simulations that focus their search efforts into areas of highest risk for disease appearance and/or escape (e.g., disease may be more likely to slip by at lower-density stopover sites).

For management agencies tasked with preventing potential human impacts from animal-borne diseases, there exists a delicate balance between reducing alpha error (i.e., missing a disease when it is present) at the expense of increased beta error (i.e., false warnings of an impending outbreak). Yet, detecting a disease before it breaks out across large geographic areas, as well as prescribing the appropriate mitigation efforts, could prove impossible without sufficient foresight. Modeling scenarios of biological connectivity from real-world observations could be a powerful, economical, and effective tool to forecast plausible events like the simplified disease transmission and evolution model presented in this chapter. Such information may provide a critical head start in developing and testing potential mitigation strategies. Not only could these models predict what metrics to track during an emerging outbreak or mitigation effort, but they could also define what natural variation may be expected, so that the process can be evaluated in real time to inform where shifts in approach may be needed. It could also pinpoint critical points in the detection and reporting infrastructure, such as a need to rapidly but accurately test for disease within fresh samples at field sites. 
Once a disease is detected, possible mitigation strategies could encompass a suite of labor-intensive, socially disruptive, or fiscally expensive management techniques that would be publicly unpopular if they were not objectively supported by a predictive framework. ABMs can repeatedly gauge the probability that, for instance, waterfowl migration would link subsequent stopover nodes within a disease network and what outcomes may be anticipated from various mitigation approaches. These data could provide managers the necessary information to justifiably focus their actions where they could most likely have the intended effect of stopping the disease outbreak. Again, such models could be continually refined and tested as the real-world situation changes and could be accomplished in the field on laptop computers.

\subsection{Refining our Migration Connectivity and Disease Monitoring ABM}

As with any model, the accuracy of the ABM simulations depends upon the realism of the rules and parameters used in their construction. Our example was, after all, a simulated case study which generalized the migratory characteristics of typical waterfowl species (see Sect. 2). The worst-case scenario presented contrasted prior evaluations of HPAI incidence among migratory birds crossing the Bering Strait, which found little evidence of the disease (Ip et al. 2008; Winker et al. 2007). It may be that avian-borne diseases could enter a continent through a number of different pathways (Peterson et al. 2007), and revisiting our ABM in light of contrasting ground observations is simply another way that this tool can be refined to simulate increasingly realistic scenarios.

Furthermore, our ABM did not account for other possible factors that would likely affect the interplay between migration biology and HPAI disease dynamics. For example, missing were possible mediating factors such as competition between low and highly pathogenic influenza strains (Bourouiba et al. 2011), behavioral avoidance of symptomatic conspecifics (Loehle 1995), stopover duration relative to disease shedding (Gaidet et al. 2010; Feare 2010), impairments among diseased individuals (van Gils et al. 2007; Kuiken 2013), or a full parameterization of density-dependent interactions, especially within small groups (Runge and Marra 2005). On the other hand, the ABM also omitted possible disease-promoting factors such as viral tenacity in the environment (Stallknecht and Brown 2009), crossspecies transmission (Kilpatrick et al. 2006; Boyce et al. 2009; Altizer et al. 2011), and in-flight stopover/aggregation decisions (Alerstam 2011). Variables likely to have context-dependent implications for disease spread, such as seasonal or daily variation in stopover suitability (Bauer and Hoye 2014) or host energetic condition (Beldomenico and Begon 2009; Arsnoe et al. 2011), were also not considered in the $\mathrm{ABM}$, and such factors could have drastic effects depending on their timing and spatial patterning along the migratory route. With respect to the monitoring and detection of the disease, here our ABM also disregarded possible extenuating variables, such as interobserver or station variability in search efficiency, local 
environmental conditions, irregular schedules, and asymmetric detectability of symptomatic individuals. In Box 17.1, we outline these possible additions to our $\mathrm{ABM}$, with brief descriptions of how each might affect the model outcomes.

\section{Box 17.1 Outline of possible extensions of the ABM presented in the chapter that would incorporate increasing realism into the simulation. This list is not intended to be encompassing but a glimpse into how ABM approaches can be as complex as desired (though at the possible expense of resolvability among possible independent variable effects).}

\begin{tabular}{|c|c|c|c|}
\hline $\begin{array}{l}\text { Candidate } \\
\text { variables }\end{array}$ & $\begin{array}{l}\text { Relevance to host } \\
\text { migration or } \\
\text { susceptibility }\end{array}$ & $\begin{array}{l}\text { Relevance to disease } \\
\text { transmission or } \\
\text { detection }\end{array}$ & $\begin{array}{l}\text { Potential data } \\
\text { sources (with } \\
\text { examples) }\end{array}$ \\
\hline \multicolumn{4}{|c|}{ Alternate transmission pathways } \\
\hline Cross-species & $\begin{array}{l}\text { Community } \\
\text { composition at } \\
\text { stopover sites and } \\
\text { interspecific } \\
\text { interactions may be } \\
\text { important }\end{array}$ & $\begin{array}{l}\text { Domestic fowl may } \\
\text { be important stores } \\
\text { and sources of } \\
\text { pathogenic disease } \\
\text { (Kilpatrick et al. } \\
\text { 2006); passerines are } \\
\text { overlooked as } \\
\text { potential carriers of } \\
\text { avian influenza } \\
\text { (Fuller et al. 2010) }\end{array}$ & $\begin{array}{l}\text { Genetic tests of } \\
\text { cross-species } \\
\text { infections (Lam et al. } \\
\text { 2012); disease } \\
\text { surveys across } \\
\text { multiple species } \\
\text { (Winker et al. 2007); } \\
\text { species association } \\
\text { data }\end{array}$ \\
\hline $\begin{array}{l}\text { Continental } \\
\text { entry points }\end{array}$ & $\begin{array}{l}\text { Multiple pathways } \\
\text { by which species } \\
\text { might cross, entering } \\
\text { different migratory } \\
\text { pathways }\end{array}$ & $\begin{array}{l}\text { Greater range of } \\
\text { possible disease } \\
\text { entry corridors }\end{array}$ & $\begin{array}{l}\text { Circumcontinental } \\
\text { monitoring networks } \\
\text { (Peterson et al. } \\
\text { 2007); integrative } \\
\text { individual tracking } \\
\text { studies (Bowlin } \\
\text { et al. 2010) }\end{array}$ \\
\hline $\begin{array}{l}\text { Environmental } \\
\text { deposition and } \\
\text { uptake }\end{array}$ & $\begin{array}{l}\text { Susceptible } \\
\text { individuals may not } \\
\text { be able to avoid } \\
\text { exposure through } \\
\text { behavioral avoidance } \\
\text { of symptomatic birds }\end{array}$ & $\begin{array}{l}\text { Leading edge of } \\
\text { migration may be } \\
\text { exposed to latent } \\
\text { virus spores at } \\
\text { stopover sites }\end{array}$ & $\begin{array}{l}\text { Viral tenacity studies } \\
\text { at points across the } \\
\text { migratory corridor } \\
\text { (Stallknecht and } \\
\text { Brown 2009) }\end{array}$ \\
\hline \multicolumn{4}{|c|}{ Refined monitoring network } \\
\hline $\begin{array}{l}\text { Variable effort } \\
\text { and observer } \\
\text { effects }\end{array}$ & $\begin{array}{l}\text { Stopover } \\
\text { aggregations could } \\
\text { be disrupted by } \\
\text { observer approach; } \\
\text { potentially exposes } \\
\text { sick individuals that } \\
\text { cannot escape }\end{array}$ & $\begin{array}{l}\text { Increased lag period } \\
\text { between disease } \\
\text { arrival and detection } \\
\text { by site monitors; } \\
\text { elevated } \\
\text { conspicuousness of } \\
\text { symptomatic birds }\end{array}$ & $\begin{array}{l}\text { Existing monitoring } \\
\text { station schedules and } \\
\text { coverages (Harris } \\
\text { et al. 2015); } \\
\text { experimental } \\
\text { detection } \\
\text { probabilities using } \\
\text { test drills }\end{array}$ \\
\hline $\begin{array}{l}\text { East-Asian } \\
\text { monitoring sites }\end{array}$ & $\begin{array}{l}\text { Area of flyway } \\
\text { overlap and molting } \\
\text { grounds; provide }\end{array}$ & $\begin{array}{l}\text { Monitoring effort } \\
\text { centered closer to the } \\
\text { known locations of }\end{array}$ & $\begin{array}{l}\text { Existing monitoring } \\
\text { effort distributions in } \\
\text { East Asia (Okazaki }\end{array}$ \\
\hline
\end{tabular}


Box 17.1 (continued)

\begin{tabular}{|c|c|c|c|}
\hline & $\begin{array}{l}\text { data on initial } \\
\text { demography, } \\
\text { energetic condition, } \\
\text { and community } \\
\text { composition }\end{array}$ & $\begin{array}{l}\text { recent HPAI } \\
\text { outbreaks } \\
\text { (Alexander and } \\
\text { Brown 2009; Prosser } \\
\text { et al. 2011) }\end{array}$ & $\begin{array}{l}\text { et al. 2000; Xu et al. } \\
\text { 2013) }\end{array}$ \\
\hline \multicolumn{4}{|c|}{ Demographically specific metrics } \\
\hline $\begin{array}{l}\text { Navigation } \\
\text { ability }\end{array}$ & $\begin{array}{l}\text { Age, sex, size, and } \\
\text { health impacts on the } \\
\text { speed and route } \\
\text { efficiency of } \\
\text { individuals }\end{array}$ & $\begin{array}{l}\text { Certain demographic } \\
\text { classes may be more } \\
\text { likely to wander } \\
\text { further or stopover } \\
\text { longer, which could } \\
\text { affect exposure and } \\
\text { recovery dynamics }\end{array}$ & $\begin{array}{l}\text { Individual tracking } \\
\text { studies using satellite } \\
\text { transmitters (Gilbert } \\
\text { et al. 2010) or } \\
\text { geolocators (Bridge } \\
\text { et al. 2011) }\end{array}$ \\
\hline $\begin{array}{l}\text { Disease } \\
\text { pathology }\end{array}$ & $\begin{array}{l}\text { Age, sex, size, and } \\
\text { health impacts on the } \\
\text { disease susceptibility } \\
\text { of individuals }\end{array}$ & $\begin{array}{l}\text { Virus transmittal } \\
\text { may be aided or } \\
\text { muted depending } \\
\text { upon the } \\
\text { demographic } \\
\text { composition of the } \\
\text { stopover population }\end{array}$ & $\begin{array}{l}\text { Challenge studies of } \\
\text { different age classes, } \\
\text { species, or sexes } \\
\text { (Pantin-Jackwood } \\
\text { et al. 2007) }\end{array}$ \\
\hline $\begin{array}{l}\text { Density- } \\
\text { dependent } \\
\text { interactions }\end{array}$ & $\begin{array}{l}\text { Density elevates } \\
\text { agonistic interactions } \\
\text { and redistribution to } \\
\text { suboptimal } \\
\text { locations; predation } \\
\text { risk tracks } \\
\text { population density }\end{array}$ & $\begin{array}{l}\text { Increased disease } \\
\text { competition within } \\
\text { dense populations as } \\
\text { low-pathogenic } \\
\text { strains may inoculate } \\
\text { hosts (Bourouiba } \\
\text { et al. 2011) }\end{array}$ & $\begin{array}{l}\text { Behavioral ecology } \\
\text { in migrant } \\
\text { aggregations (Runge } \\
\text { and Marra 2005); } \\
\text { time-allocation } \\
\text { budgets (Morales } \\
\text { et al. 2010) }\end{array}$ \\
\hline \multicolumn{4}{|c|}{ Condition-dependent factors } \\
\hline $\begin{array}{l}\text { Disease } \\
\text { susceptibility }\end{array}$ & $\begin{array}{l}\text { Migratory birds may } \\
\text { be more susceptible } \\
\text { to disease during } \\
\text { molting periods or } \\
\text { under other stressors } \\
\text { (Feare 2010; Fuller } \\
\text { et al. 1998) }\end{array}$ & $\begin{array}{l}\text { Virus transmittal } \\
\text { may be aided or } \\
\text { muted depending } \\
\text { upon the condition of } \\
\text { the exposed } \\
\text { individual } \\
\text { (Beldomenico and } \\
\text { Begon 2009) }\end{array}$ & $\begin{array}{l}\text { Condition-dependent } \\
\text { challenge studies } \\
\text { (Arsnoe et al. 2011) }\end{array}$ \\
\hline $\begin{array}{l}\text { Functional } \\
\text { impairment }\end{array}$ & $\begin{array}{l}\text { Migratory } \\
\text { movements affected } \\
\text { by infections, even } \\
\text { when asymptomatic } \\
\text { (van Gils et al. 2007) }\end{array}$ & $\begin{array}{l}\text { Disease has } \\
\text { relatively narrow } \\
\text { window to infect } \\
\text { hosts and spread to } \\
\text { other populations } \\
\text { (Gaidet et al. 2010) }\end{array}$ & $\begin{array}{l}\text { Test physiological } \\
\text { effects among } \\
\text { infected birds } \\
\text { (Kuiken 2013); track } \\
\text { in-flight physiology } \\
\text { (Gumus et al. 2015) }\end{array}$ \\
\hline \multicolumn{4}{|c|}{ Migration biology factors } \\
\hline $\begin{array}{l}\text { In-flight } \\
\text { decisions }\end{array}$ & $\begin{array}{l}\text { Migratory birds are } \\
\text { capable of } \\
\text { continually assessing } \\
\text { underlying } \\
\text { landscapes for }\end{array}$ & $\begin{array}{l}\text { Greater potential for } \\
\text { disease spread within } \\
\text { attractive stopover } \\
\text { habitats and among }\end{array}$ & $\begin{array}{l}\text { Real-time individual } \\
\text { stopover choices } \\
\text { relative to dynamic } \\
\text { landscape factors } \\
\text { and ground-truthed }\end{array}$ \\
\hline
\end{tabular}


Box 17.1 (continued)

\begin{tabular}{|c|c|c|c|}
\hline & $\begin{array}{l}\text { conspecific } \\
\text { aggregations or } \\
\text { suitable habitat }\end{array}$ & $\begin{array}{l}\text { conspecific } \\
\text { groupings }\end{array}$ & $\begin{array}{l}\text { population metrics } \\
\text { (Kays et al. 2015) }\end{array}$ \\
\hline $\begin{array}{l}\text { Fat stores and } \\
\text { replenishment }\end{array}$ & $\begin{array}{l}\text { Migrants will be } \\
\text { constrained to } \\
\text { stopover for a } \\
\text { duration inversely } \\
\text { related to habitat } \\
\text { quality }\end{array}$ & $\begin{array}{l}\text { Prolonged stopovers, } \\
\text { particularly } \\
\text { low-quality habitats, } \\
\text { could promote } \\
\text { disease exposure }\end{array}$ & $\begin{array}{l}\text { Monitor individual } \\
\text { stopover duration } \\
\text { relative to } \\
\text { underlying habitat } \\
\text { (Takekawa et al. } \\
\text { 2010) }\end{array}$ \\
\hline \multicolumn{4}{|c|}{ Spatiotemporal landscape variability } \\
\hline $\begin{array}{l}\text { Seasonal shifts } \\
\text { in resources }\end{array}$ & $\begin{array}{l}\text { Climate-mediated } \\
\text { resource } \\
\text { competition; greater } \\
\text { motivation for } \\
\text { migration toward } \\
\text { suitable wintering } \\
\text { habitat (see } \\
\text { Chap. 16) }\end{array}$ & $\begin{array}{l}\text { Virus spread must } \\
\text { match host's speed } \\
\text { toward wintering } \\
\text { ground; } \\
\text { spatiotemporal } \\
\text { patterns in stressors } \\
\text { promoting infection }\end{array}$ & $\begin{array}{l}\text { Incorporate seasonal } \\
\text { shifts in population } \\
\text { distributions and } \\
\text { resource availability } \\
\text { across the migratory } \\
\text { season (Bauer and } \\
\text { Hoye 2014) }\end{array}$ \\
\hline $\begin{array}{l}\text { Daily weather } \\
\text { patterns }\end{array}$ & $\begin{array}{l}\text { Locally mediated } \\
\text { resource } \\
\text { competition; dictates } \\
\text { exodus, pathway, } \\
\text { and stopover } \\
\text { decisions (see } \\
\text { Chaps. } 8 \text { and 12) }\end{array}$ & $\begin{array}{l}\text { Cycle of host } \\
\text { immigration and } \\
\text { emigration at } \\
\text { stopover sites may } \\
\text { ensure a constant } \\
\text { supply of potential } \\
\text { hosts }\end{array}$ & $\begin{array}{l}\text { Relate archived } \\
\text { weather data to } \\
\text { existing daily } \\
\text { stopover site data for } \\
\text { numbers and } \\
\text { diversity of birds } \\
\text { infected (Winker and } \\
\text { Gibson 2010) }\end{array}$ \\
\hline \multicolumn{4}{|c|}{ Host-disease evolutionary models } \\
\hline $\begin{array}{l}\text { Viral mutability } \\
\text { and balancing } \\
\text { selection }\end{array}$ & $\begin{array}{l}\text { Greater } \\
\text { parameterization of } \\
\text { host responses to } \\
\text { viral exposure, } \\
\text { including } \\
\text { immunocompetent } \\
\text { plasticity } \\
\text { (Beldomenico and } \\
\text { Begon 2009) }\end{array}$ & $\begin{array}{l}\text { Underlying genetic } \\
\text { variation and } \\
\text { spatiotemporal } \\
\text { mutation } \\
\text { probabilities can } \\
\text { drive the pathology } \\
\text { of avian influenza } \\
\text { disease (Boyce et al. } \\
\text { 2009) }\end{array}$ & $\begin{array}{l}\text { Incorporate complex } \\
\text { algorithms } \\
\text { associated with } \\
\text { competition-driven } \\
\text { evolution } \\
\text { (DeAngelis and } \\
\text { Mooij 2005) }\end{array}$ \\
\hline
\end{tabular}

\subsection{Future Directions for Aeroecological Network Analyses Using ABMs}

Biological processes occurring in the aerosphere are diverse and mediated by a plethora of intrinsic and external factors. The application of ABMs to such a largescale and complex system will necessarily require increasingly greater parameterization based upon real-world measurements. Fortunately, as evinced by the wealth 
of knowledge presented in the other chapters of this volume, researchers are continuing to increase our knowledge base of ecological processes occurring in the aerosphere, especially as we gain the capability to track how individuals move through this medium and the resulting impacts on population connectivity and landscape permeability.

Aeroecology often revolves around the collection and analysis of so-called big data. While the analysis of such large datasets is daunting, access to increasingly powerful computational hardware is allowing us to fully leverage the power of ABM framework to deconstruct, model, and ultimately understand the complex processes underlying the airspace oddity that is life on the wing. For example, ABMs could readily be applied to broad-scale ecological questions such as the latitudinal redistribution of energy and nutrient resources by migratory animals (Bauer and Hoye 2014). That said, there does exist the potential to overparameterize an $\mathrm{ABM}$ at the expense of resolvability among the rapidly expanding realm of variables and interactions. The advantage that the ABM simulation framework allows in isolating specific variables for the purpose of conducting sensitivity analyses could easily be swamped by an overabundance of independent variables. A simple ABM, such as we've presented in this chapter, can provide valuable insights even when it has omitted some variables or has not incorporated all related data during its parameterization (MacPherson and Gras 2016).

The powered flight of animals can rapidly and extensively connect biological communities, including pathogens, across the face of the world. A more thorough understanding of how this connectivity operates can have profound ecological and anthrosocial implications. This is especially true within the modern era, as wild animals are increasingly forced into close association with rapidly growing human population centers and the concentrated animal feeding operations that have become the primary source of domesticated food. How might the future aeroecological patterns affect such human-wildlife conflicts? We believe that ABMs show promise to bind together what we are learning about the global-scale and circannual patterns that comprise aeroecology, as we continue to construct a mosaicked understanding of this yet-emerging scientific discipline.

\section{References}

Alerstam T (2003) Bird Migration Speed. In: Berthold P, Gwinner E, Sonnenschein E (eds) Avian Migration. Springer, Berlin. https://doi.org/10.1007/978-3-662-05957-9_17

Alerstam T (2011) Optimal bird migration revisited. J Ornithol 152:5-23. https://doi.org/10.1007/ s10336-011-0694-1

Alerstam T, Hedenstrom A, Akesson S (2003) Long-distance migration: evolution and determinants. Oikos 103:247-260

Alerstam T, Baeckman J, Gudmundsson GA et al (2007) A polar system of intercontinental bird migration. Proc R Soc B Biol Sci. https://doi.org/10.1098/rspb.2007.0633

Alexander DJ, Brown IH (2009) History of highly pathogenic avian influenza. Rev Sci Tech 28:19-38 
Altizer S, Bartel R, Han BA (2011) Animal migration and infectious disease risk. Science 331:296-302

Arsnoe DM, Ip HS, Owen JC (2011) Influence of body condition on influenza a virus infection in mallard ducks: experimental infection data. PLoS One 6:1-10. https://doi.org/10.1371/journal. pone.0022633

Azziz-Baumgartner E, Smith N, González-Alvarez R et al (2009) National pandemic influenza preparedness planning. Influenza Other Respi Viruses 3:189-196. https://doi.org/10.1111/j. 1750-2659.2009.00091.x

Bairlein F, Norris DR, Nagel R et al (2012) Cross-hemisphere migration of a $25 \mathrm{~g}$ songbird. Biol Lett 8:505-507. https://doi.org/10.1098/rsbl.2011.1223

Balicer RD, Reznikovich S, Berman E et al (2007) Multifocal avian influenza (H5N1) Outbreak. Emerg Infect Dis 13:1601-1603. https://doi.org/10.3201/eid1310.070558

Bauer S, Hoye BJ (2014) Migratory animals couple biodiversity and ecosystem functioning worldwide. Science 344:1242552. https://doi.org/10.1126/science.1242552

Beldomenico PM, Begon M (2009) Disease spread, susceptibility and infection intensity: vicious circles? Trends Ecol Evol 25:21-27. https://doi.org/10.1016/j.tree.2009.06.015

Bellrose FC, Crompton RD (1970) Migrational behavior of mallards and black ducks as determined from banding. Ill Nat Hist Surv Bull 30:167-234

Bourouiba L, Teslya A, Wu J (2011) Highly pathogenic avian influenza outbreak mitigated by seasonal low pathogenic strains: insights from dynamic modeling. J Theor Biol 271:181-201. https://doi.org/10.1016/j.jtbi.2010.11.013

Bowlin MS, Bisson I-A, Shamoun-Baranes J et al (2010) Grand challenges in migration biology. Integr Comp Biol 50:261-279. https://doi.org/10.1093/icb/icq013

Boyce WM, Sandrock C, Kreuder-Johnson C et al (2009) Avian influenza viruses in wild birds: a moving target. Comp Immunol Microbiol Infect Dis 32:275-286. https://doi.org/10.1016/j. cimid.2008.01.002

Bridge ES, Thorup K, Bowlin MS et al (2011) Technology on the move: recent and forthcoming innovations for tracking migratory birds. Bioscience 61:689-698. https://doi.org/10.1525/bio. 2011.61.9.7

Brown JD, Stallknecht DE (2008) Wild bird surveillance for the avian influenza virus. Methods Mol Biol 436:85-97. https://doi.org/10.1007/978-1-59745-279-3_11

Brown JD, Stallknecht DE, Beck JR et al (2006) Susceptibility of North American ducks and gulls to H5N1 highly pathogenic avian influenza viruses. Emerg Infect Dis 12:1663-1670. https:// doi.org/10.3201/eid1211.060652

Brown JD, Stallknecht DE, Swayne DE (2008) Experimental infection of swans and geese with highly pathogenic avian influenza virus (H5N1) of Asian lineage. Emerg Infect Dis J 14:136. https://doi.org/10.3201/eid1401.070740

Cagnacci F, Boitani L, Powell RA, Boyce MS (2010) Animal ecology meets GPS-based radiotelemetry: a perfect storm of opportunities and challenges. Philos Trans R Soc Lond B Biol Sci 365:2157-2162

CEC - Commission for Environmental Cooperation (2007) North America elevation 1-kilometer resolution, 3rd edn. http://www.cec.org/Atlas/Files/elevation/Elevation_Layer_Package.zip. Accessed 6 June 2015

CEC - Commission for Environmental Cooperation (2010) North American Atlas - hydrography, 2009 revision. http://www.cec.org/Atlas/Files/Rivers_and_Lakes/Rivers_and_Lakes_Layer_ Package.zip. Accessed 23 Sept 2013

Choffnes ER, Sparling PF, Hamburg MA et al (2007) Global infectious disease surveillance and detection: assessing the challenges - finding solutions, Workshop Summary. National Academies Press

Cooke SJ, Hinch SG, Wikelski M et al (2004) Biotelemetry: a mechanistic approach to ecology. Trends Ecol Evol 19:334-343. https://doi.org/10.1016/j.tree.2004.04.003

Dau CP (1992) The fall migration of pacific flyway Brent Branta bernicla in relation to climatic conditions. Wildfowl 43:80-95 
DeAngelis DL, Mooij WM (2005) Individual-based modeling of ecological and evolutionary processes. Annu Rev Ecol Evol Syst 36:147-168

DeLiberto TJ, Swafford S, Why K Van (2011) Development of a national early eetection system for highly pathogenic avian influenza in wild birds in the United States of America. USDA National Wildlife Research Center - Staff Publications

Delmore KE, Irwin DE (2014) Hybrid songbirds employ intermediate routes in a migratory divide. Ecol Lett 17:1211-1218. https://doi.org/10.1111/ele.12326

Ellis EC, Ramankutty N (2008) Putting people in the map: anthropogenic biomes of the world. Front Ecol Environ 6. https://doi.org/10.1890/070062. http://www.cec.org/Atlas/Files/Anthro pogenic_Biomes/Anthromes_Layer_Package_GRID.zip. Accessed 20 Sept 2013

Ely CR, Franson JC (2014) Blood lead concentrations in Alaskan tundra swans: linking breeding and wintering areas with satellite telemetry. Ecotoxicology 23:349-356. https://doi.org/10. 1007/s10646-014-1192-z

Ely CR, Douglas DC, Fowler AC, Babcock CA, Derksen DV, Takekawa JY (1997) Migration behavior of Tundra Swans from the Yukon-Kuskokwim Delta, Alaska. Wilson Bull 109 (4):679-692

ESRI (2012) World continents. ESRI, Redlands

European Centre for Disease Prevention and Control (ECDC) (2007) Technical Report: Pandemic Influenza Preparedness in the EU. Status Report as of Autumn 2006

Feare CJ (2010) Role of wild birds in the spread of highly pathogenic avian influenza virus H5N1 and implications for global surveillance. Avian Dis 54:201-212

Ferguson NM, Cummings DAT, Fraser C et al (2006) Strategies for mitigating an influenza pandemic. Nature 442:448-452

Flock WL (1972) Radar observations of bird migration at Cape Prince of Wales. Arctic 25:83-98

Fuller MR, Seegar WS, Schueck LS (1998) Routes and travel rates of migrating Peregrine Falcons Falco peregrinus and Swainson's Hawks Buteo swainsoni in the Western Hemisphere. J Avian Biol 29:433-440. https://doi.org/10.2307/3677162

Fuller TL, Saatchi SS, Curd EE, Toffelmier E, Thomassen HA, Buermann W, DeSante DF et al (2010) Mapping the risk of Avian Influenza in wild birds in the US. BMC Infect Dis 10(1):187. https://doi.org/10.1186/1471-2334-10-187. (BioMed Central)

Franklin AB, Anderson DR, Burnham KP (2002) Estimation of long-term trends and variation in avian survival probabilities using random effects models. J Appl Stat 29(1-4):267-287. https:// doi.org/10.1080/02664760120108719. (Taylor \& Francis)

Gaidet N, Cappelle J, Takekawa JY et al (2010) Potential spread of highly pathogenic avian influenza $\mathrm{H} 5 \mathrm{~N} 1$ by wildfowl: dispersal ranges and rates determined from large-scale satellite telemetry. J Appl Ecol 47:1147-1157. https://doi.org/10.1111/j.1365-2664.2010.01845.x

Gilbert M, Xiao X, Domenech J et al (2006) Anatidae migration in the western Palearctic and spread of highly pathogenic avian influenza H5N1 virus. Emerg Infect Dis 12:1650-1656. https://doi.org/10.3201/eid1211.060223

Gilbert M, Newman SH, Takekawa JY, Loth L, Biradar C, Prosser DJ, Balachandran S et al (2010) Flying over an infected landscape: distribution of highly pathogenic Avian Influenza H5N1 risk in South Asia and satellite tracking of wild waterfowl. EcoHealth 7(4):448-458. https:// doi.org/10.1007/s10393-010-0672-8

Green M, Alerstam T, Clausen P et al (2002) Dark-bellied Brent Geese Branta bernicla bernicla, as recorded by satellite telemetry, do not minimize flight distance during spring migration. Ibis 144:106-121. https://doi.org/10.1046/j.0019-1019.2001.00017.x

Gumus A, Lee S, Ahsan SS et al (2015) Lab-on-a-Bird: biophysical monitoring of flying birds. PLoS One 10:e0123947

Harris RJ, Reed JM (2002) Behavioral barriers to non-migratory movements of birds. Ann Zool Fennici 39:275-290

Harris MC, Miles AK, Pearce JM et al (2015) USGS highly pathogenic avian influenza research strategy: U.S. Geological Survey Fact Sheet 2015-3060, 4 p

Hebblewhite M, Haydon DT (2010) Distinguishing technology from biology: a critical review of the use of GPS telemetry data in ecology. Philos Trans R Soc Lond B Biol Sci 365:2303-2312 
Hobson KA, Ryan Norris D (2008) Tracking animal migration with stable isotopes. Terr Ecol 2:1-19. https://doi.org/10.1016/S1936-7961(07)00001-2

Hulse-Post DJ, Sturm-Ramirez KM, Humberd J et al (2005) Role of domestic ducks in the propagation and biological evolution of highly pathogenic H5N1 influenza viruses in Asia. Proc Natl Acad Sci USA 102:10682-10687. https://doi.org/10.1073/pnas.0504662102

Ip HS, Flint PL, Franson JC et al (2008) Prevalence of influenza A viruses in wild migratory birds in Alaska: patterns of variation in detection at a crossroads of intercontinental flyways. Virol $\mathrm{J}$ 5:71. https://doi.org/10.1186/1743-422X-5-71

Irwin DE (2002) Phylogeographic breaks without geographic barriers to gene flow. Evolution 56:2383-2394. https://doi.org/10.1111/j.0014-3820.2002.tb00164.x

Jebara KB (2004) Surveillance, detection and response: managing emerging diseases at national and international levels. Rev Sci Tech 23:709-715

Kapan DD, Bennett SN, Ellis BN et al (2006) Avian influenza (H5N1) and the evolutionary and social ecology of infectious disease emergence. Ecohealth 3:187-194. https://doi.org/10.1007/ s10393-006-0044-6

Kays R, Crofoot MC, Jetz W, Wikelski M (2015) Terrestrial animal tracking as an eye on life and planet. Science 348:aaa2478

Keeling MJ, Rohani P (2008) Modeling infectious diseases in humans and animals. Princeton University Press, Princeton

Kilpatrick AM, Chmura AA, Gibbons DW et al (2006) Predicting the global spread of H5N1 avian influenza. Proc Natl Acad Sci USA 103:19368-19373. https://doi.org/10.1073/pnas. 0609227103

Kjellén N, Hake M, Alerstam T (2001) Timing and speed of migration in male, female and Juvenile Ospreys Pandion haliaetus between Sweden and Africa as revealed by field observations, radar and satellite tracking. J Avian Biol 32:57-67

Krementz DG, Asante K, Naylor LW (2012) Autumn migration of Mississippi Flyway Mallards as determined by satellite telemetry. J Fish Wildl Manag 3:238-251. https://doi.org/10.3996/ 022012-JFWM-019

Kuiken T (2013) Is low pathogenic avian influenza virus virulent for wild waterbirds? Proc Biol Sci 280:20130990. https://doi.org/10.1098/rspb.2013.0990

Lam TT-Y, Ip HS, Ghedin E et al (2012) Migratory flyway and geographical distance are barriers to the gene flow of influenza virus among North American birds. Ecol Lett 15:24-33. https:// doi.org/10.1111/j.1461-0248.2011.01703.x

Loehle C (1995) Social barriers to pathogen transmission in wild animal populations. Ecology 76:326-335. https://doi.org/10.2307/1941192

MacPherson B, Gras R (2016) Individual-based ecological models: adjunctive tools or experimental systems? Ecol Modell 323:106-114. https://doi.org/10.1016/j.ecolmodel.2015.12.013

McKinnon EA, Fraser KC, Stutchbury BJM (2013) New discoveries in landbird migration using geolocators, and a flight plan for the future. Auk 130:211-222. https://doi.org/10.1525/auk. 2013.12226

Moermond JE, Spindler MA (1997) Migration route and wintering area of Tundra Swans Cygnus columbianus nesting in the Kobuk-Selawik Lowlands, North-West Alaska. Wildfowl 48:16-25

Morales JM, Moorcroft PR, Matthiopoulos J et al (2010) Building the bridge between animal movement and population dynamics. Philos Trans R Soc Lond B Biol Sci 365:2289-2301

Mosbech A, Gilchrist G, Merkel F et al (2006) Year-round movements of northern common eiders Somateria mollissima breeding in Arctic Canada and West Greenland followed by satellite telemetry. Ardea 94:651-665

Okazaki K, Takada A, Ito T et al (2000) Precursor genes of future pandemic influenza viruses are perpetuated in ducks nesting in Siberia. Arch Virol 145:885-893. https://doi.org/10.1007/ s007050050681

Olsen B, Munster VJ, Wallensten A et al (2006) Global patterns of influenza A virus in wild birds. Science 312:384-388 
Pantin-Jackwood MJ, Suarez DL, Spackman E, Swayne DE (2007) Age at infection affects the pathogenicity of Asian highly pathogenic avian influenza H5N1 viruses in ducks. Virus Res 130:151-161. https://doi.org/10.1016/j.virusres.2007.06.006

Pérez-Tris J, Bensch S, Carbonell R et al (2004) Historical diversification of migration patterns in a Passerine bird. Evolution 58:1819-1832. https://doi.org/10.1111/j.0014-3820.2004.tb00464.x

Peterson AT, Benz BW, Papeş M (2007) Highly pathogenic H5N1 avian influenza: entry pathways into North America via bird migration. PLoS One 2:e261. https://doi.org/10.1371/journal. pone. 0000261

Peterson AT, Andersen MJ, Bodbyl-Roels S et al (2009) A prototype forecasting system for birdborne disease spread in North America based on migratory bird movements. Epidemics 1:240-249. https://doi.org/10.1016/j.epidem.2009.11.003

Prosser DJ, Takekawa JY, Newman SH et al (2009) Satellite-marked waterfowl reveal migratory connection between H5N1 outbreak areas in China and Mongolia. Ibis (Lond 1859) 151:568-576. https://doi.org/10.1111/j.1474-919X.2009.00932.x

Prosser DJ, Cui P, Takekawa JY et al (2011) Wild bird migration across the Qinghai-Tibetan plateau: a transmission route for highly pathogenic H5N1. PLoS One 6:e17622

Pybus OG, Fraser C, Rambaut A (2013) Evolutionary epidemiology: preparing for an age of genomic plenty. Philos Trans R Soc Lond B Biol Sci 368:540-550

Robinson WD, Bowlin MS, Bisson I et al (2010) Integrating concepts and technologies to advance the study of bird migration. Front Ecol Environ 8:354-361. https://doi.org/10.1890/080179

Runge M, Marra P (2005) Modeling seasonal interactions in the population dynamics of migratory birds. In: Greenberg R, Marra PP (eds) Birds of two worlds: the ecology and evolution of migration. Johns Hopkins University Press, Baltimore, pp 375-390

Scallan E (2007) Activities, achievements, and lessons learned during the first 10 years of the foodborne diseases active surveillance network: 1996-2005. Clin Infect Dis 44:718-725. https://doi.org/10.1086/511648

Shariatinajafabadi M, Wang T, Skidmore AK et al (2014) Migratory herbivorous waterfowl track satellite-derived green wave index. PLoS One 9:e108331

Si Y, Xin Q, de Boer WF et al (2015) Do arctic breeding geese track or overtake a green wave during spring migration? Sci Rep 5:8749

Silkavute P, Tung DX, Jongudomsuk P (2013) Sustaining a regional emerging infectious disease research network: a trust-based approach. Emerg Health Threats J 6. https://doi.org/10.3402/ ehtj.v6i0.19957

Stallknecht DE, Brown JD (2009) Tenacity of avian influenza viruses. Rev Sci Tech 28:59-67

Sutherland GD, Harestad AS, Price K, Lertzman KP (2000) Scaling of natal dispersal distances in terrestrial birds and mammals. Conserv Ecol 4:16

Takekawa JY, Newman SH, Xiao X et al (2010) Migration of waterfowl in the East Asian Flyway and spatial relationship to HPAI H5N1 outbreaks. Avian Dis 54:466-476. https://doi.org/10. 1637/8914-043009-Reg.1

Takekawa JY, Prosser DJ, Collins BM et al (2013) Movements of wild ruddy shelducks in the Central Asian Flyway and their spatial relationship to outbreaks of highly pathogenic avian influenza H5N1. Viruses 5:2129-2152. https://doi.org/10.3390/v5092129

Tan K-X, Jacob SA, Chan K-G, Lee L-H (2015) An overview of the characteristics of the novel avian influenza A H7N9 virus in humans. Front Microbiol 6:1-11. https://doi.org/10.3389/ fmicb.2015.00140

Tang W, Bennett DA (2010) Agent-based modeling of animal movement: a review. Geogr Compass 4:682-700. https://doi.org/10.1111/j.1749-8198.2010.00337.x

Taubenberger JK, Kash JC (2016) Influenza virus evolution, host adaptation, and pandemic formation. Cell Host Microbe 7:440-451. https://doi.org/10.1016/j.chom.2010.05.009

Taylor PD, Fahrig L, Henein K, Merriam G (1993) Connectivity is a vital element of landscape structure. Oikos 68:571-573. https://doi.org/10.2307/3544927

Van Der Plank JE (1963) Plant diseases: epidemics and control. Academic, New York 
van Gils JA, Munster VJ, Radersma R et al (2007) Hampered foraging and migratory performance in swans infected with low-pathogenic avian influenza A virus. PLoS One 2:e184. https://doi. org/10.1371/journal.pone.0000184

von Rönn JAC, Shafer ABA, Wolf JBW (2016) Disruptive selection without evolution across a migratory divide. Mol Ecol. https://doi.org/10.1111/mec.13521

Wagner MM, Tsui F-C, Espino JU et al (2001) The emerging science of very early detection of disease outbreaks. J Public Heal Manag Pract 7:51-59

WCS/CIESIN - Wildlife Conservation Society and Center for International Earth Science Information Network (2005) Last of the Wild Data Version 2 (LWP-2): Global human footprint dataset (geographic). http://www.cec.org/Atlas/Files/Human_Influence_Terrestrial/ HumanInfluenceTerrestrial_Layer_Package_GRID.zip. Accessed 20 Sept 2013

Wiens JA (1976) Population responses to patchy environments. Annu Rev Ecol Syst 7:81-120

Winker K, Gibson DD (2010) The Asia-to-America influx of avian influenza wild bird hosts is large. Avian Dis 54:477-482. https://doi.org/10.1637/9192-874109-DIGEST.1

Winker K, McCracken KG, Gibson DD et al (2007) Movements of birds and avian influenza from Asia into Alaska. Emerg Infect Dis 13:547-552. https://doi.org/10.3201/eid1304.061072

Wobeser GA (2013) Investigation and management of disease in wild animals. Springer Science and Business Media, New York

Xu C, Havers F, Wang L et al (2013) Monitoring avian influenza A(H7N9) virus through national influenza-like illness surveillance, China. Emerg Infect Dis J 19:1289. https://doi.org/10.3201/ eid1908.130662

Yang Y, Halloran ME, Sugimoto JD, Longini IM (2007) Detecting human-to-human transmission of avian influenza A (H5N1). Emerg Infect Dis 13:1348-1353. https://doi.org/10.3201/ eid1309.070111

Zink RM (1996) Comparative phylogeography in North American birds. Evolution 50:308-317. https://doi.org/10.2307/2410802 